Research Article

\title{
Why and How Does a Supplier Choose Factoring Finance?
}

\author{
Chunying Tian, ${ }^{1}$ Dongyan Chen $\left(\mathbb{D},{ }^{2}\right.$ Zhaobo Chen, ${ }^{3}$ and Ding Zhang ${ }^{4}$ \\ ${ }^{1}$ School of Economy and Management, Harbin University of Science and Technology, Harbin, China \\ ${ }^{2}$ School of Science, Harbin University of Science and Technology, Harbin 150080, China \\ ${ }^{3}$ Key Research Bases for Humanities and Social Sciences in Shanxi: Research Center for Innovation \\ and Development of Equipment Manufacturing Industry, Taiyuan University of Science and Technology, \\ Taiyuan 030024, China \\ ${ }^{4}$ School of Business, State University of New York, Oswego, NY 13126, USA \\ Correspondence should be addressed to Dongyan Chen; dychen_2004@hotmail.com
}

Received 13 September 2019; Revised 21 November 2019; Accepted 14 December 2019; Published 13 January 2020

Academic Editor: Konstantina Skouri

Copyright ( $\odot 2020$ Chunying Tian et al. This is an open access article distributed under the Creative Commons Attribution License, which permits unrestricted use, distribution, and reproduction in any medium, provided the original work is properly cited.

\begin{abstract}
Suppliers offering trade credit to the downstream retailers have to face many problems, such as receivables management, capital occupancy, and buyer's credit risk. Many of them choose factoring finance to solve those problems simultaneously. This paper develops several supply chain decision models to show the benefits a supplier can obtain from the main functions of factoring and how he should choose between recourse factoring and nonrecourse factoring. In particular, we identify the conditions on which factoring may bring benefits (including financial benefit, guarantee benefit, and receivables management benefit) to the supplier. The supplier's choice between recourse and nonrecourse factoring relies on his risk attitude. Given that the supplier is risk-neutral and the factoring fees are acceptable, recourse factoring is preferred when the factoring finance ratio is relatively high; otherwise, nonrecourse factoring is preferred. However, if the supplier is risk-averse, his preference for the two factoring schemes under different finance ratios may change when the risk constraints become stricter. If the target profit is lower than a certain level, the supplier's financial choice will switch from recourse factoring to nonrecourse factoring in the case finance ratio is relatively low; otherwise, his financial choice switches from nonrecourse factoring to recourse factoring in the case finance ratio is relatively high.
\end{abstract}

\section{Introduction}

Regarded as a promotion method, a settlement form, a product quality assurance, and a financing channel, trade credit has absorbed attentions of scholars in many fields including marketing, international trade, corporation management, and finance. However, with the development of a new research branch-interface of finance, operations, and risk management [1], people begin to study trade credit in a supply chain framework and emphasize its operational implications. According to the researchers in this field, when supply chain participants make their operational and financial decisions simultaneously, not only each member but also the whole supply chain's efficiency may increase significantly. In this sense, trade credit is valuable to the supply chain because it serves as a distribution mechanism that makes the risk and profit of the supply chain reallocated among supply chain members. Although positive effects of trade credit have been studied intensively, its deficiency has seemed to be ignored. When extending trade credit to a downstream retailer, the supplier has to face many additional problems: (a) specialized branches or employees are needed to perform accounts receivable management; (b) cash flow locked in the accounts receivable generates a considerable financial cost; and (c) the retailer may lose repayment ability due to the uncertainty of market demand. A potential approach to mitigate or relieve the supplier's problems caused by providing trade credit is factoring. Actually, factoring is a comprehensive financial service that includes credit protection, accounts receivable bookkeeping, collection services, and financing [2]. In practice, since the end of the last century, the global factoring industry has grown at a relatively fast pace, increasing on average nearly 9\% per annum (ICC 2017). 
Among all the functions, accounts receivable management is the primary activity of factoring companies. Except for credit-administration personnel and techniques, factors always possess highly specialized industry knowledge. Many firms, especially small firms with limited capital to invest in the credit administration department, can outsource their credit management function to factors to take advantage of their superior resources [3]. Furthermore, empirical studies have indicated the existence of scale economies in credit granting and credit collection, which means a large factor is more efficient than several smaller firm-maintained credit departments [4]. Hence, it is reasonable to believe that, in many cases, the factors can monitor the retailer and manage the accounts receivable in a more efficient way [5-7]. As the recovery rate of accounts receivable is decided by the creditors' monitoring intensity [8], a higher recovery rate can be achieved when the factor takes charge of the accounts receivable.

While the receivables management function has been in use for a long time, the recent expansion of factoring, especially since the great financial crisis of 2008, should attribute more to its financing function [9]. Factoring finance is especially attractive to small- and medium-sized enterprises, because they are allowed to receive immediate cash without involving in loan collateralization or increasing in firm liabilities [10]. In practice, factoring can be done on a recourse basis or nonrecourse basis; the difference between the two schemes lies in whether the factor has a claim against the supplier for the account payment deficiency. In nonrecourse factoring, the factor does not have that claim and acts as a guarantee against the retailer's credit risk. Due to the accessibility of firms' credit information, factoring is often performed on a nonrecourse basis in developed countries; however, recourse factoring is more popular in developing countries [2].

Consequently, there are three potential benefits a supplier may enjoy if he chooses factoring finance. Our study investigates the performance implications of factoring finance for the players in a supply chain, discussing when the supplier can benefit from factoring and how he should choose between recourse and nonrecourse factoring. We adopt a stylized model with a supplier selling to a newsvendor-like retailer facing uncertain demand. The strategic interaction between the supplier and the retailer is modeled as a Stackelberg game where the supplier (the leader) decides the wholesale price and the retailer (the follower) decides the order quantity. The deal between the supplier and the retailer is done on a credit sale basis, and the accounts receivable is transferred to a factor that will monitor the retailer intensively during the selling season. Under the precondition that the factor is able to reduce the retailer's default possibility, we obtain the optimal operational decisions of the supplier and retailer when recourse factoring and nonrecourse factoring are adopted. Furthermore, we discuss which factoring scheme is dominant when the supplier is risk-neutral and risk-averse, respectively.

Our contributions are in two ways. First, the previous theoretical researches mainly focus on the financing function of factoring; thus, these literatures always explain the supplier's factoring decision based on the financing cost saving or extra capacity generated from factoring. By adding the receivables management function and guarantee function, we are able to explain the usage of factoring from a new perspective. Second, we explore a supplier's joint decisionmaking on operation and finance with the factor's comprehensive services, which is a common practical problem but has seldom been addressed by scholars. Moreover, referring to the supply chain finance literature [11-13], we take the supplier's risk attitude into account to improve the practical significance of our study.

The rest of the paper is organized as follows. In Section 2, we summarize the relationship of our paper to the literature. Section 3 describes the key elements of the problem and outlines the model assumptions. Section 4 lays out the model when there is no factoring finance as a benchmark. Section 5 develops the optimal wholesale price contracts when recourse factoring and nonrecourse factoring are adopted, respectively, and examines a risk-neutral supplier's choice between the two schemes. Section 6 discusses the effect of the supplier's risk averseness on his financing strategies and illustrates the benefits of factoring for the supplier. We conclude the paper in Section 7.

\section{Related Literature}

Our work is related to the interface of finance, operations, and risk management. Under the uncertain market demand assumption, works in this stream explain the mechanisms that trade credit improves the supply chain's efficiency [14-16] and the advantages of trade credit compared to bank credit [17-19]. All these papers focus on the situation where a supplier provides finance to a capital-constrained downstream retailer and emphasize the positive effects of trade credit to the supply chain. However, supply chains with capital-constrained suppliers are very common in practice, and many suppliers use factoring to mitigate the negative effects of trade credit.

Fortunately, with more and more scholars paying attention to this phenomenon, researches on the factoring finance witness a rapid development in recent years, especially the ones on reverse factoring. Unlike traditional factoring, where the process is focusing on working with the supplier only, in reverse factoring, the retailer acts as an underwriter of the repayment risk of the accounts receivable, enabling the factor to offer a relatively lower interest rate to the supplier. Tanrisever et al. [20] study the value of reverse factoring using a single period inventory model and obtain the supply chain members' optimal operational and financial decisions based on their participant constraints. In their settings, the benefits of factoring generate from the save in financial cost and the higher capacity and will be distributed between the members through payment period extension. Similarly, Vliet et al. [21] address how a supplier determines inventory level and payment delay jointly under reverse factoring. Vliet et al. [22] extend their previous model by considering the scenario where two retailers involve and study the supplier's rationing policy when factoring exists and show that the retailer providing reverse factoring enjoys 
a higher service level but with an upper limit. Based on [21], by trading the supplier's cash retention policy as an external parameter, Lekkakos and Serrano [23] analytically show the optimality of a base-stock policy. Tunca and Zhu [24] examine a game-theoretical model where the large retailer determines the wholesale price and order quantity simultaneously, while the supplier decides the loan amount, showing that buyer intermediated financing can significantly improve channel performance and benefit both of the supply chain participants. Although reverse factoring is more popular in literature, very few factoring transactions are done on a reverse factoring basis. Many more companies, across many industries, take advantage of traditional factoring to finance and manage their accounts receivables. According to the FCI (Factors Chain International), only $11 \%$ of the world factoring business was conducted in the reverse factoring form in 2017. So, at present, traditional factoring is still the dominant form.

However, studies on traditional factoring in supply chain finance literature are quite limited. As one of the earliest studies, Sopranzetti [8] examines the factor's pricing strategy and the seller's factoring decisions when his credit monitoring level is unobservable to the factor and finds that the seller will transfer his high credit quality receivables instead of low quality ones. Considering credit risk and exchange rate risk simultaneously, Huang and Zhang [25] conclude that there exists an optimal factoring finance ratio that will benefit both the financing bank and the enterprise. Under the constant demand assumption, $\mathrm{Li}$ and $\mathrm{Gu}$ [26] address how a firm chooses the optimal timing of discounting to minimize the factoring cost when two different factoring discounting schemes are used. They find that manual discounting is always more attractive to the firm than automatic discounting if the factoring discount rates of the two are the same. Kouvelis and $\mathrm{Xu}$ [27] develop a supply chain theory of traditional factoring (recourse and nonrecourse) and reverse factoring, showing when these postshipment financing schemes should be adopted and who really benefits from the adoption. The extant literatures on traditional factoring examine either only its receivables management function, such as Sopranzetti [8], or only its financing function, such as Huang and Zhang [25] and Kouvelis and $\mathrm{Xu}$ [27].

Different to existing researches, this work complements the supply chain factoring finance literature by encompassing both financing function and receivables management function of factoring. As guarantee function is embodied in nonrecourse factoring, we actually consider three main functions of this special financial service, which enables us to provide a comprehensive analysis of it. Besides, since the major distinction of nonrecourse and recourse is whether the factor bears part of the buyer's credit risk, we provide an analysis on how risk attitude influences the supplier's choice between the two factoring schemes.

\section{Model Description and Main Assumptions}

3.1. Model Description. Consider a two-layer supply chain with a retailer (she) requesting to delay payment until the end of the selling season and a capital-constrained supplier (he) whose capital cost is considerably high (because of low credit rating). To decrease financial expenditure and avoid the buyer's credit risk, the supplier decides to finance from a factor (it) (suppose that the supplier is allowed to pay for the materials until he gets the prepayment from the factor). The sequence of the events is shown in Figure 1.

At the beginning, the supplier announces the wholesale price $w$ and informs the retailer of the factoring plan. To respond, the retailer decides the order quality $q$. After the credit sale contract is signed, the supplier transfers the accounts receivable to the factor in exchange for immediate cash $\lambda w q / 1+r_{k}$, where $\lambda$ represents the financing ratio of the factor and $r_{k}$ refers to the factoring service fee charged ahead ( $k=1$ or 2 means recourse or nonrecourse factoring, respectively). Note that $r_{k}$ includes not only the financing interest but also fees for other services provided by the factor. In the case where the factor's financing amount is inadequate to cover the total production cost $c q$, the supplier uses his expensive working capital (with average interest rate $r_{0}$ ) to pay for the rest. The retailer sells the products at retail price $p$ in a market where the demand is stochastic, and the salvage value of the unsold inventory is zero. At the end of the selling season, if the retailer's revenue is insufficient to meet her debt obligation $w q$, there exists a subjective default possibility of the retailer, which depends on the management ability of the creditor (the supplier or the factor). In the situation where the retailer chooses to default, if the realized revenue is sufficient to repay the factor's prepayment, the leftover part goes to the supplier; otherwise, the factor will request the supplier to pay back its unrecovered advance in a recourse factoring arrangement but has to bear the losses in a nonrecourse one.

3.2. Notations and Assumptions. The uncertain demand is denoted by a random variable $D$, whose support is $[0,+\infty)$. The probability density function of $D$ is $f(D)$, the cumulative distribution function (CDF) is $F(D)$, and the complementary CDF is $\bar{F}(D)=1-F(D)$. For technical purposes, we follow the supply chain financing literature and assume that the demand distribution has a strictly increasing failure rate $h(D)=f(D) / \bar{F}(D)$ that is also convex [28]. The generalized failure rate (GFR) is defined as $H(D)=D h(D)$.

In both recourse and nonrecourse factoring contract, the factor is requested to manage the accounts receivable and monitor the retailer intensively, and the related fees are included in $r_{k}$. Suppose that there is no information asymmetry between the supplier and the factor; the factor must execute the same monitoring policy no matter it has recourse or not. Consequently, the retailer's default probabilities under the two factoring schemes remain equal. Let $0<m \leq 1$ be the probability that the retailer repays to the creditor in the case her sale proceeds are less than the trade credit obligation when the supplier takes charge of the accounts receivable, and let $0<M \leq 1$ be that probability when the factor manages the receivables. As argued in Zhang et al. [29], $m \neq 0$ (or $M \neq 0)$ indicates that 


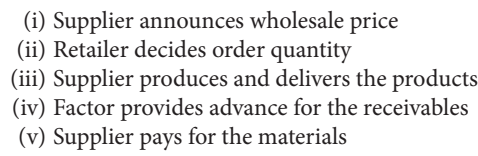

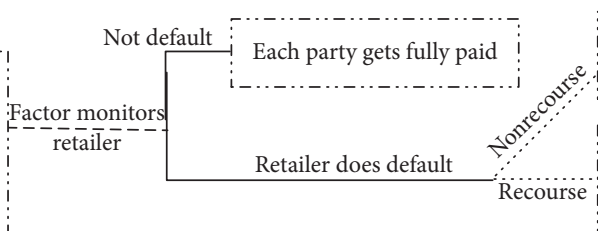

(i) Factor is paid from the realized revenue

(i) Factor is paid from the realized revenue (ii) Supplier gets the leftover part if possible

(iii) Factor requests the supplier to repay the uncovered prepayment if there is any

Figure 1: Sequences of events.

the retailer also takes part of the market risk; therefore, she deserves to share the profit with the supplier. In the case where $m=0$, the supplier will set the wholesale price at the retail price, since he bears the market risk and buyer's credit risk all by himself (see Jing et al. [18] for detail). In addition, we use the assumption $M \geq m$ to capture the economic gist that the factor owns comparative advantages in account receivables management.

The notations are summarized in Table 1 . In general, we use subscripts 0,1 , and 2 for no factoring finance, recourse factoring finance, and nonrecourse factoring finance, respectively. Besides, we use subscript “*” for the optimal solutions solving the decision-makers' first-order conditions and subscript " $\wedge$ " for the solutions obtained from the supplier's risk constraints.

For convenience, we present the following assumptions, and these assumptions are reasonable from an economics perspective.

Assumption 1. All parameters are common knowledge to the supplier, the retailer, and the factor.

Assumption 2. The average interest rate of the supplier's working capital is higher than factoring finance, while the financing fee of recourse factoring is lower than that of nonrecourse factoring; that is, $r_{0}>r_{2}>r_{1}$.

In fact, the factoring cost rate is nearly 5 percentage points above the average bank interest rate [2], so there are chances that $r_{2}$ (or $r_{1}$ ) is higher than $r_{0}$. We still adopt the high $r_{0}$ assumption, because we use "high financial cost" instead of "limited working capital" to capture the supplier's capital constraint. The discrepancy in service fees between recourse factoring and nonrecourse factoring generates from the different rights of the factor under the two schemes. When the realized market demand is insufficient to cover the factor's prepayment and the retailer defaults, it has right to request the supplier to repay the uncovered part under recourse factoring but has no such right under nonrecourse factoring. Hence, nonrecourse factoring contract is more risky for the factor than the recourse one, even though the retailer's default probabilities are equal. The factor then asks for a higher service fee to balance its extra risk under nonrecourse factoring. This assumption is also in line with the factoring finance practice. According to RTS international, a famous factoring institute in USA, nonrecourse factoring is more expensive than recourse factoring by as much as a full percentage point.
Table 1: Notation.

\begin{tabular}{ll}
\hline$p$ & $\begin{array}{l}\text { Retailer's retail price of the product (we normalize } \\
c=1)\end{array}$ \\
$w_{i}$ & $\begin{array}{l}\text { Supplier's unit production cost; } 0<c \leq 1 \\
\text { Supplier's decision variable, the wholesale price; } \\
c \leq w_{i} \leq 1, \text { for } i=0,1,2\end{array}$ \\
$q_{i}$ & $\begin{array}{l}\text { Retailer's decision variable, the order quantity, for } \\
i=0,1,2\end{array}$ \\
$z_{i}$ & Total amount of the accounts receivable, for $i=0,1,2$ \\
$r_{0}$ & Cost of the supplier's working capital \\
$\pi_{i} / \Pi_{i}$ & $\begin{array}{l}\text { The retailer's/supplier's expected profit, for } i=0,1,2 \\
\text { The probability that the retailer does not default when }\end{array}$ \\
$m / M$ & $\begin{array}{l}\text { her sale revenue is insufficient to repay her } \\
\text { obligations under the supplier's/the factor's }\end{array}$ \\
$\lambda$ & $\begin{array}{l}\text { supervision } \\
\text { Factor's financing ratio to the supplier; } 0<\lambda \leq 1\end{array}$ \\
$\beta$ & $\begin{array}{l}\text { Supplier's target profit level when he is risk-averse } \\
\text { The specified threshold in which the supplier keeps } \\
\text { the probability that his actual profit falls below target }\end{array}$ \\
& profit not exceeds.
\end{tabular}

\section{No Factoring Benchmark}

In this section, as a benchmark, we analyze the scenario where the supplier does not adopt factoring but manages the accounts receivable all by himself. As the supplier and retailer act as Stackelberg game players in our setting, following the standard backward induction approach, we start by characterizing the optimal ordering quantity of the retailer. Then, we analyze how the supplier chooses the optimal wholesale price anticipating the retailer's best response.

4.1. The Retailer's Optimal Decision. Given the wholesale price $w_{0}$, the retailer chooses an order quantity $q_{0}$, leading to a trade credit amount $w_{0} q_{0}$. At the end of the period, the retailer yields revenue $\min \left\{D, q_{0}\right\}$ (recall that the retail price is normalized to 1 ). If the sale realized is insufficient to cover the accounts receivable (i.e., $D<w_{0} q_{0}$ ), since the retailer fulfills her liability to repay the supplier with probability $m$, her net expected payoff is $m\left(D-w_{0} q_{0}\right)$. Otherwise, she will have $D-w_{0} q_{0}$ in the case $w_{0} q_{0} \leq D<q_{0}$ and $q_{0}-w_{0} q_{0}$ in the case $D \geq q_{0}$. Thus, the retailer's expected profit can be expressed as

$$
\pi_{0}=\int_{w_{0} q_{0}}^{q_{0}} \bar{F}(D) \mathrm{d} D-\int_{0}^{w_{0} q_{0}} m F(D) \mathrm{d} D .
$$

The second item of (1) does not exist in the previous literature with the retailer's limited liability assumption, 
where the retailer orders more than she would if she is endowed with sufficient capital [18]. As we suppose that the retailer meets her obligation with probability $m$, the more she orders the larger her contingent obligation becomes. Thus, we can predict that the retailer will shrink her procurement strategy in this situation. The following proposition characterizes the retailer's optimal order quantity and its main properties.

Proposition 1. For any given wholesale price $w_{0}$, the optimal order quantity of the retailer $q_{0}^{*}$ is given by the following equation:

$$
\bar{F}\left(q_{0}^{*}\right)=(1-m) w_{0} \bar{F}\left(w_{0} q_{0}^{*}\right)+m w_{0},
$$

and (1) $q_{0}^{*}$ decreases in $w_{0}$ and (2) there exists a $\widetilde{w}_{0}$ satisfying $q_{0}^{*}\left(\widetilde{w}_{0}\right)=\widetilde{q}$ such that when $w_{0}<\widetilde{w}_{0}, q_{0}^{*}>\widetilde{q}$ and $w_{0} q_{0}^{*}$ increases in $w_{0}$; in contrast, $q_{0}^{*} \leq \widetilde{q}$ and $w_{0} q_{0}^{*}$ decreases in $w_{0}$, where $\widetilde{q}$ solves $H(\widetilde{q})=1$.

All proofs are in the Appendix.

From equation (2), the retailer's expected marginal revenue depends not only on the trade credit amount and the market demand but also on the probability that she fulfills her liability, which can also be seen as the ratio of the total liabilities that the retailer will definitely repay. Similar to previous literature, the retailer always decreases procurement when the wholesale price gets higher. However, the changes of the trade credit amount according to the wholesale price depend on whether the order quantity exceeds $\tilde{q}$, that is, whether the GFR is larger than 1. In Lariviere and Porteus [30], GFR gives (roughly) the percentage decrease in the probability of a stock out from increasing the stocking quantity by $1 \%$. So, to some extent, it reflects the risk level of the supply chain participants. The result that $q_{0}^{*}>\widetilde{q}$ holds if only $w_{0}<\widetilde{w}_{0}$ means the retailer is able to bear high risk only when the cost is low. Also, the existence of an upper boundary of $w_{0} q_{0}^{*}$ indicates that the retailer always keeps her total debt at a feasible level.

4.2. The Supplier's Optimal Decision. Anticipating the retailer's response, the supplier chooses $w_{0}$ to maximize his expected profit. Since the supplier will receive $(1-m) D+$ $m w_{0} q_{0}$ when the demand is too low for the retailer to meet her obligation and $w_{0} q_{0}$ when the demand is high, his expected profit (after rearrangement) can be written as

$$
\Pi_{0}=\int_{0}^{w_{0} q_{0}}(1-m) \bar{F}(D) \mathrm{d} D+m w_{0} q_{0}-c q_{0}\left(1+r_{0}\right) .
$$

Let $w_{0}^{*}$ be the optimal wholesale price the supplier will set; Proposition 2 shows $w_{0}^{*}$ can be determined by the firstorder condition of the supplier.

Proposition 2. When the supplier sells on credit, his optimal wholesale price $w_{0}^{*}$ solves $\eta_{0}\left(w_{0}^{*}\right)=1$, where

$$
\eta_{0}\left(w_{0}^{*}\right)=\frac{1}{c\left(1+r_{0}\right)} \frac{\left[(1-m) \bar{F}\left(w_{0}^{*} q_{0}^{*}\right)+m\right] \bar{F}\left(q_{0}^{*}\right)\left[1-H\left(q_{0}^{*}\right)\right]}{(1-m) \bar{F}\left(w_{0}^{*} q_{0}^{*}\right)\left[1-H\left(w_{0}^{*} q_{0}^{*}\right)\right]+m} .
$$

According to the equilibrium condition of the supplier, $H\left(q_{0}^{*}\right)<1$ always holds, which means the supplier will set a wholesale price that leads the retailer to order no more than $\widetilde{q}$. That is, even if the retailer intends to take a risky strategy to order more, the attempt may be destroyed by the supplier. Let $\delta=\bar{F}\left(q_{0}^{*}\right)\left[1-H\left(q_{0}^{*}\right)\right]$ and $\theta=(1-m) \bar{F}$ $\left(w_{0}^{*} q_{0}^{*}\right)+m /(1-m) \bar{F}\left(w_{0}^{*} q_{0}^{*}\right)\left[1-H\left(w_{0}^{*} q_{0}^{*}\right)\right]+m$; then the condition $\eta_{0}\left(w_{0}^{*}\right)=1$ is equivalent to $c\left(1+r_{0}\right)=\delta \theta$. Here, the left hand $c\left(1+r_{0}\right)$ represents the supplier's marginal cost, while the right hand can be explained as the adjusted marginal revenue (recall the retail price is assumed to be 1 ). While $\delta$ captures the market risk, $\theta$ reflects the retailer's profit requirement and the subjective default risk simultaneously.

\section{Supply Chain Members' Operational Strategies with Factoring Finance}

When the supplier transfers the accounts receivable to the factor, the retailer will be monitored by the factor. To avoid reputation loss, the retailer will voluntarily decrease her default probability. On the other hand, the factor, who owns a professional advantage, can execute more intensive monitoring to avoid the retailer's default. Hence, the retailer's subjective default probability decreases from $1-m$ to $1-M$; accordingly, her optimal response to the supplier's wholesale price can be expressed as

$$
\bar{F}\left(q_{i}^{*}\right)=(1-M) w_{i} \bar{F}\left(w_{i} q_{i}^{*}\right)+M w_{i}, \quad i=1,2 .
$$

As shown in the proof of Proposition 1, the lower the probability of default is the less procurement the retailer makes. Thus, the retailer reduces her order quantity when factoring is adopted, causing the decrease in the profit of the supplier (see the proof of Lemma 1 for details).

5.1. Recourse Factoring Scenario. Once the supplier sells his accounts receivable to the factor with recourse, he receives immediate cash to pay for the production cost. The discrepancy between the cost and the factor's prepayment needs to be met by his own working capital. Due to the nature of resource factoring, the supplier is responsible for the uncollected amount of the factor at the end of the payment period. Therefore, the supplier's expected profit can be expressed as

$$
\begin{aligned}
\Pi_{1}= & \int_{0}^{w_{1} q_{1}}\left[(1-M) D+M w_{1} q_{1}-\lambda w_{1} q_{1}\right] \mathrm{d} F(D) \\
& +\int_{w_{1} q_{1}}^{+\infty}\left(w_{1} q_{1}-\lambda w_{1} q_{1}\right) \mathrm{d} F(D) \\
& +\left(\frac{\lambda w_{1} q_{1}}{1+r_{1}}-c q_{1}\right)\left(1+r_{0}\right) .
\end{aligned}
$$

Similar to proposition (2), the optimal wholesale price of the supplier satisfies 


$$
\frac{\left[(1-M) \bar{F}\left(w_{1}^{*} q_{1}^{*}\right)+M+\lambda\left(\left(1+r_{0}\right) /\left(1+r_{1}\right)-1\right)\right] \bar{F}\left(q_{1}^{*}\right)\left[1-H\left(q_{1}^{*}\right)\right]}{(1-M) \bar{F}\left(w_{1}^{*} q_{1}^{*}\right)\left[1-H\left(w_{1}^{*} q_{1}^{*}\right)\right]+M} \frac{1}{c\left(1+r_{0}\right)}=1
$$

Except for the retailer's default probability, the difference of equation (7) from the no factoring benchmark is the item $\lambda\left(\left(1+r_{0}\right) /\left(1+r_{1}\right)-1\right)$, which measures the save in capital cost through factoring. Since the factor does not share risk with the supplier, financing is the only benefit the supplier can expect from factoring besides accounts receivable management. However, because the retailer, as aforementioned, tends to reduce her procurement under the stricter monitoring of the factor, the financial benefit should be large enough to offset the "lose." The following lemma provides the condition under which the supplier will accept the recourse factoring contract.

Lemma 1. For any given $M$, we can always find ranges of $\lambda$ and $r_{1}$ that make recourse factoring acceptable to the supplier.

In most of the supply chain finance literature, the supplier or the retailer's capital constraint is described by the limited capital endowment, and their optimal financial decisions depend on the level of their initial capital. However, in our setting, the precondition that the supplier is capital-constrained is expressed by his high capital cost. Hence, the supplier's choice of factoring finance relies on whether the factor can offer sufficient cash with a relatively favorable fee.

5.2. Nonrecourse Factoring Scenario. In the nonrecourse factoring scenario, the factor cannot request the supplier to repay the fund it offered at the beginning of the selling season, acting as a guarantor for the retailer's credit risk. In the case $D \leq \lambda w_{2} q_{2}$, the supplier gets the remaining receivable $w_{2} q_{2}-\lambda w_{2} q_{2}$ with probability $M$ and gets nothing with probability $1-M$ at the end of the selling season. In the case $\lambda w_{2} q_{2}<D \leq w_{2} q_{2}$, the supplier may still get full repayment with probability $M$ but may receive $D-\lambda w_{2} q_{2}$ with probability $1-M$. Finally, if $D>w_{2} q_{2}$, the supplier can always be fully repaid. Then, the supplier's expected profit can be expressed as

$$
\begin{aligned}
\Pi_{2}= & \int_{\lambda w_{2} q_{2}}^{w_{2} q_{2}}(1-M)\left(D-\lambda w_{2} q_{2}\right) \mathrm{d} F(D) \\
& +\int_{w_{2} q_{2}}^{\infty}(1-M)(1-\lambda) w_{2} q_{2} \mathrm{~d} F(D)+M(1-\lambda) w_{2} q_{2} \\
& +\left(\frac{\lambda w_{2} q_{2}}{1+r_{2}}-c q_{2}\right)\left(1+r_{0}\right) .
\end{aligned}
$$

By organizing the items, we have

$$
\begin{aligned}
\Pi_{2}= & \int_{\lambda w_{2} q_{2}}^{w_{2} q_{2}}(1-M) \bar{F}(D) \mathrm{d} D+M w_{2} q_{2}+(1-M) \lambda w_{2} q_{2} \\
& +\left(\frac{1+r_{0}}{1+r_{2}}-1\right) \lambda w_{2} q_{2}-c q_{2}\left(1+r_{0}\right) .
\end{aligned}
$$

Then, the optimal wholesale price of the supplier satisfies

$$
\frac{(1-M) \bar{F}\left(w_{2}^{*} q_{2}^{*}\right)+M+(1-M) \lambda F\left(\lambda w_{2}^{*} q_{2}^{*}\right)+\lambda\left(\left(1+r_{0}\right) /\left(1+r_{2}\right)-1\right)}{\left\{\left[(1-M) \bar{F}\left(w_{2}^{*} q_{2}^{*}\right)\left(1-H\left(w_{2}^{*} q_{2}^{*}\right)\right)+M\right] /\left[\bar{F}\left(q_{2}^{*}\right)\left(1-H\left(q_{2}^{*}\right)\right)\right]\right\} c\left(1+r_{0}\right)}=1
$$

By comparing equation (10) with equation (7), we find the supplier's optimal decision has a new added item $(1-M) \lambda F\left(\lambda w_{2}^{*} q_{2}^{*}\right)$, which is devoted to raising the supply chain's total output. That is because the guarantee function of nonrecourse factoring motivates the supplier to execute a riskier strategy. However, since there is no free lunch, the factor would ask for a higher service fee for this additional service, which has a negative impact on the supplier's decision.

Similar to Lemma 1, there exist feasible ranges of $r_{2}$ and $\lambda$ such that nonrecourse factoring dominates no factoring benchmark. That is, the supplier's profit will increase if he adopts nonrecourse factoring when either $\lambda$ is relatively high or $r_{2}$ is relatively low.

\subsection{Supplier's Choice between Recourse and Nonrecourse} Factoring. As shown previously, with the factor taking charge of the accounts receivable, the retailer may be more conservative in her procurement activity, causing a decrease in the supplier's profit. Fortunately, the "deficiency" can be offset by the financial function of factoring. Both recourse 
factoring and nonrecourse factoring are valuable when certain conditions are satisfied. Then, the supplier has to choose between the two factoring schemes. Proposition 3 demonstrates that when the nonrecourse factoring service fee is acceptable, the supplier's choice depends on the factoring finance ratio.

Proposition 3. If the nonrecourse factoring fee is lower than $\bar{r}_{2}$, which satisfies $\left.\Pi_{2}^{*}\right|_{\lambda=1}=\left.\Pi_{1}^{*}\right|_{\lambda=1}$, there must exist a threshold of factoring finance ratio $\bar{\lambda}$ such that if $\lambda<\bar{\lambda}$, the supplier prefers recourse factoring; otherwise, he prefers nonrecourse factoring.

From the proof of Proposition 3, we notice the increase of the supplier's expected profit under recourse factoring when $\lambda$ gets larger attributes only to the reduction in the supplier's financing cost. However, with nonrecourse factoring, the raise of $\lambda$ improves the supplier's profit in two ways. Besides reducing the financial expenditure, it protects the supplier against severe losses in the case the demand realized is lower than $\lambda w_{2}^{*} q_{2}^{*}$. Correspondingly, the factor bears the risk for the supplier. As $\lambda$ influences the allocation of credit risk between the supplier and the factor, it is crucial in the supplier's factoring decision. In practice, suppliers with different credit ratings have access to different finance ratios; the higher the suppliers' creditworthiness is, the larger $\lambda$ they enjoy. Thus, credit-worthy suppliers tend to choose nonrecourse factoring.

Proposition 3 also argues that nonrecourse factoring can be dominant if only $r_{2}$ is lower than certain upper boundary, which explains the popularity of nonrecourse factoring in developed economies to some extent. In developing countries, as the credit rating system is not established completely, financial institutions are not able to gain the exact creditworthiness information of a firm, leading to a high factoring fee of nonrecourse factoring. While a relative lower $r_{2}$ is acceptable to the supplier, it may damage the benefit of the factor. Since Proposition 3 only addresses the feasible service fees of nonrecourse factoring from the supplier's perspective, it is necessary to confirm whether those fees are acceptable to the factor too. The following lemma discusses the conditions under which $r_{2}$ can also be accepted by the factor.

Lemma 2. When the cost of the supplier's working capital $r_{0}$ is higher than a certain level, the nonrecourse factoring service fees acceptable to the supplier will also make the factor at least break-even.

Lemma 2 indicates that the supplier and the factor have more chance to come to an agreement on nonrecourse factoring service fee when the supplier's capital cost is high. From the proof of Lemma 2, when the supplier's capital is expensive, he always tends to make a conservative strategy, which will in turn decrease the factor's financing risk and ensure the nonnegative expected profit of the factor. We focus our attention on these cases only in this paper.

\section{A Risk-Averse Supplier's Factoring Finance Strategy}

In the above analysis, it is shown that the monitoring advantage of the factor may restrict the supply chain's output level and conduct a negative effect on a risk-neutral supplier's performance. In fact, many firms care more about risks than profits, and they are usually willing to trade off lower expected profit for downside protection against possible losses. Consequently, a risk-averse supplier's operational decision is different from that of a risk-neutral one. In this section, we are going to see that the receivables management function of factoring is more valuable to a riskaverse supplier. To add a risk control mechanism to the problem mentioned above, we suppose the supplier adopts a downside risk strategy. Notice that the supplier always produces at a level equal to the retailer's order quantity by anticipating the retailer's response to his wholesale price decision. Thus, we will use the supplier's production amount and the retailer's order quantity interchangeably in the remaining parts of this paper.

As Gan et al. [12], we consider the downside risk of a newsvendor as the probability that the realized profit is less than or equal to his specified target profit. Let $\alpha$ denote the target profit; the supplier's downside risk constraint can be expressed as

$$
P\{\text { revenue }-\operatorname{cost} \leq \alpha\} \leq \beta .
$$

When using (11) to capture the supplier's risk attitude, one thing is noticeable here. In Gan et al. [12], the newsvendor's realized profit is decided by the stochastic market demand D only; as a result, the "revenue" there is a definite value according to a certain $D$. But, in our setting, the randomness of the supplier's profit is caused not only by the market demand but also by the retailer's subjective default risk. Thus, the downside risk would be expressed by a joint probability of the two events. However, as most of the literatures considering the player's risk attitude refer "risk" to market risk only, to correspond to them, we incorporate the retailer's subjective default as a coefficient of the sale proceeds and describe the "revenue" in (11) as an expected value.

From inequality (11), the supplier's risk constraint is decided by $\alpha$ and $\beta$. Consider two risk aversion pairs $\left\{\alpha_{1}, \beta_{1}\right\}$ and $\left\{\alpha_{2}, \beta_{2}\right\}$; if $\alpha_{1} \leq \alpha_{2}$ and $\beta_{1} \geq \beta_{2}$, then the second pair means a higher aversion to risk than the first one does. On the left hand of (11), the supplier's profit depends not only on his production decision but also on the market demand. There exists production quantity $\bar{q}_{i}$ (recall that $i$ denotes different financial arrangements) such that the supplier's profit equals $\alpha$ if $D=\bar{q}_{i}$; then in the cases $D<\bar{q}_{i}$, the supplier's profit is always lower than $\alpha$. That is, if $\beta$ is lower than $F\left(\bar{q}_{i}\right)$ (the probability that the market demand is lower than $\left.\bar{q}_{i}\right)$, there is no feasible solution to (11). Otherwise, with the risk-aversion pair $\{\alpha, \beta\}$, whether the supplier's former optimal decision $q_{i}^{*}$ meets the risk constraint depends on the value of $\alpha$ and $\beta$. Imagine that, for given $\alpha, \beta$ being high enough, the supplier still chooses $q_{i}^{*}$ as his optimal strategy; otherwise, he must produce less to reduce the chance that he 
cannot realize his target profit. Thus, there is an upper boundary $\hat{q}_{i}(\alpha, \beta)$ that the supplier's production quantity should not exceed.

6.1. The Effect of Factor's Management Advantage on a RiskAverse Supplier. Before discussing a risk-averse supplier's operational and financial strategies, we firstly address the question "whether the factor's strict monitoring on the retailer is valuable for a risk-averse supplier." To do so, we consider the case where $\lambda=0$. In this situation, the only difference between factoring and no factoring is the retailer's default probability $1-m$ and $1-M$. Our analysis is conducted by checking on how the upper boundary of the supplier's production quantity changes according to $m$.

Lemma 3. For a given risk-aversion pair $\{\alpha, \beta\}$, the upper boundary $\widehat{q}_{0}$ increases in $m$ if $\widehat{w}_{0} \widehat{q}_{0} \bar{F}\left(\widehat{w}_{0} \widehat{q}_{0}\right)>F^{-1}(\beta)$.

Lemma 3 shows that, even without considering the financial function of factoring, it is also attractive when the supplier is risk-averse, because when $q_{0}^{*}$ cannot meet the risk constraint, $q_{1}^{*}$ or $q_{2}^{*}$ may not be constrained. The precondition $\widehat{w}_{0} \widehat{q}_{0} \bar{F}\left(\widehat{w}_{0} \widehat{q}_{0}\right)>F^{-1}(\beta)$ is a sufficient condition, reflecting that the monitoring function (or receivables management function) helps to reduce the risk of an operational strategy when the production scale of supply chain reaches a high level.

However, even if $q_{1}^{*}$ or $q_{2}^{*}$ is also unreachable, the factoring contract can still be accepted if $r_{1}, r_{2}$, and $\lambda$ are favorable. So, in the next part of this section, we are going to study how a risk-averse supplier chooses between recourse and nonrecourse factoring. For simplicity, we use $z_{i}$ to denote the total amount of the accounts receivable from here until the end of the paper; that is, $z_{i}=w_{i} q_{i}$.

6.2. A Risk-Averse Supplier's Factoring Choice. In Proposition 3 , the advantage of one factoring scheme depends on the level of $\Pi_{i}^{*}$; however, when risk constraint is considered, the supplier's first-order condition may be not realizable anymore; a new standard is needed to judge the comparative advantage of one scheme over the other one. In fact, comparison of $q_{1}^{*}$ and $q_{2}^{*}$ can be used as the new standard. Because the risk constraint always requests the supplier's output level not to exceed a certain level, the lower $q_{i}^{*}$ is, the smaller the chance that it becomes infeasible due to risk constraint. Lemma 4 provides some insights to our further analysis.

Lemma 4. For a fixed $\lambda$, there is only one $q^{\#}$ satisfying $\Pi_{1}\left(q^{\#}\right)=\Pi_{2}\left(q^{\#}\right)$. Let $\lambda_{1}$ and $\lambda_{2}$ solve $q_{1}^{*}=q^{\#}$ and $q_{2}^{*}=q^{\#}$, respectively; then we have $\underline{\lambda} \leq \lambda_{2} \leq \bar{\lambda} \leq \lambda_{1}$ (refer to the proof of Proposition 3 for the definitions of $\underline{\lambda}$ and $\bar{\lambda}$ ); moreover

$$
\begin{cases}q_{2}^{*} \leq q_{1}^{*}<q^{\#}, & \text { if } \lambda \leq \underline{\lambda}, \\ q_{1}^{*}<q_{2}^{*} \leq q^{\#}, & \text { if } \underline{\lambda}<\lambda \leq \lambda_{2}, \\ q_{1}^{*} \leq q^{\#}<q_{2}^{*}, & \text { if } \lambda_{2}<\lambda \leq \lambda_{1}, \\ q^{\#}<q_{1}^{*}<q_{2}^{*}, & \text { if } \lambda_{1}<\lambda \leq 1 .\end{cases}
$$

We can infer from Lemma 4 that when $\lambda$ is large, even though $\Pi_{2}^{*}$ is higher than $\Pi_{1}^{*}$, the higher $q_{2}^{*}$ may injure the advantage of nonrecourse factoring. Similarly, the recourse factoring may lose its dominance when $\lambda$ is small. Notice that Lemma 4 also provides the relative level of $q_{i}^{*}$ compared to $q^{\#}$, which allows us to compare $\Pi_{i}^{*}$ or $\widehat{\Pi}_{i}$ with $\Pi_{3-i}^{*}$ or $\widehat{\Pi}_{3-i}\left(\widehat{\Pi}_{i}\right.$ is the supplier's expected profit at $q_{i}=\widehat{q}_{i}$, and $i=1$ or 2 here), making it possible for us to find the supplier's global optimal strategy easily when certain downside-risk constraint is given.

The downside-risk constraint of the supplier is influenced by $\alpha$ and $\beta$, so the levels of these two parameters determine whether $q_{i}^{*}$ is still achievable. Notice that when adopting nonrecourse factoring, the supplier at least receives $\lambda w_{2} q_{2}$ no matter what the market demand turns out to be. Therefore, he has the least profit $\Pi_{2}^{m}=M\left(z_{2}-\lambda z_{2}\right)+$ $\left(\lambda z_{2} /\left(1+r_{2}\right)-c q_{2}\right)\left(1+r_{0}\right)$ at any $q_{2}$ (actually, because of the existence of retailer's subjective default risk, the supplier may also have some assured revenue in the low-demand situation when he uses recourse factoring. We ignore this situation because we exclude the uninteresting case when the retailer's default probability is so low that the supplier can get full repayment even when $D=0$ ). If $\alpha \leq\left.\Pi_{2}^{m}\right|_{q_{2}=q_{2}^{*}}, q_{2}^{*}$ always satisfies the risk constraint. Otherwise, both $q_{1}^{*}$ and $q_{2}^{*}$ may cannot meet the constraint; that is, they may exceed the upper boundary $\widehat{q}_{i}(\alpha, \beta)$. Similar to $\widehat{q}_{0}$ in Lemma $3, \widehat{q}_{1}(\alpha, \beta)$ and $\widehat{q}_{2}(\alpha, \beta)$ solve the following equations, respectively:

$$
\frac{\alpha+c \widehat{q}_{1}\left(1+r_{0}\right)-M \widehat{z}_{1}-\left(\left(1+r_{0}\right) /\left(1+r_{1}\right)-1\right) \lambda \widehat{z}_{1}}{1-M}=F^{-1}(\beta),
$$

$\frac{\alpha+c \widehat{q}_{2}\left(1+r_{0}\right)-M \widehat{z}_{2}-\left(\left(1+r_{0}\right) /\left(1+r_{2}\right)-1\right) \lambda \widehat{z}_{2}}{1-M}=F^{-1}(\beta)$.

Equation (13) simply follows the following fact: the chance that the supplier's profit is lower than the target profit equals the chance that the market demand is lower than the level that makes him gain target profit. Compared to equation (13), equation (14) is obtained indirectly from the fact that the supplier's risk constraint is actually equivalent to $P\left\{D \leq \lambda z_{2}\right\}+P\left\{\lambda z_{2}<D \leq\left[\alpha+c q_{2}\left(1+r_{0}\right)-M z_{2}-((1+\right.\right.$ $\left.\left.\left.\left.r_{0}\right) /\left(1+r_{2}\right)-1\right) \lambda z_{2}\right] /(1-M)\right\} \leq \beta$. From equations (13) and (14), we have $\widehat{q}_{1}>\widehat{q}_{2}$. Notice that $\left[\alpha+c q_{1}\left(1+r_{0}\right)-M z_{1}-\right.$ $\left.\left(\left(1+r_{0}\right) /\left(1+r_{1}\right)-1\right) \lambda z_{1}\right] /(1-M)$ is a convex function of $q_{1}$; if its minimum is bigger than $F^{-1}(\beta)$, there is no feasible solution for the risk constraint. To focus on the interesting cases only, we ignore such extreme case in the rest of this paper. For a $\beta$ that makes equation (13) solvable, there would be two solutions. By comparing equation (13) with equation (7), we can conclude that $\widehat{q}_{1}$ is the one with positive firstorder derivative. Similar analysis can be done with $\hat{q}_{2}$.

Equations (13) and (14) show that, for any given $\beta$, there exists maximum $q$ satisfying the risk constraint. Conversely, for a given $q_{i}^{*}$, we can find the critical $\beta$ that determines whether $q_{i}^{*}$ will still be the equilibrium solution because of risk constraint. Define $\widehat{\beta}_{1}$ and $\widehat{\beta}_{2}$ as 


$$
\begin{aligned}
& \frac{\alpha+c q_{1}^{*}\left(1+r_{0}\right)-M z_{1}^{*}-\left(\left(1+r_{0}\right) /\left(1+r_{1}\right)-1\right) \lambda z_{1}^{*}}{1-M}=F^{-1}\left(\widehat{\beta}_{1}\right) \\
& \frac{\alpha+c q_{2}^{*}\left(1+r_{0}\right)-M z_{2}^{*}-\left(\left(1+r_{0}\right) /\left(1+r_{2}\right)-1\right) \lambda z_{2}^{*}}{1-M}=F^{-1}\left(\widehat{\beta}_{2}\right) .
\end{aligned}
$$

Obviously, $\widehat{\beta}_{1}$ and $\widehat{\beta}_{2}$ increase in $q_{1}^{*}$ and $q_{2}^{*}$, respectively. As the comparison between $q_{1}^{*}$ and $q_{2}^{*}$ depends on $\lambda$, there are possibilities that $\widehat{\beta}_{1}>\widehat{\beta}_{2}$ and $\widehat{\beta}_{1} \leq \widehat{\beta}_{2}$. Then, it is uncertain which one of $q_{1}^{*}$ and $q_{2}^{*}$ will be constrained. Recall that $\alpha$ is also a factor that influences the degree of the risk constraint; we give the supplier's financial choice according to $\alpha, \beta$ and $\lambda$ in Proposition 4.

Proposition 4. Compared to the case when the supplier is risk-neutral,

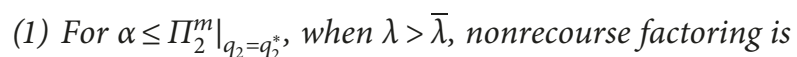
still the optimal scheme; however, when $\lambda \leq \bar{\lambda}$, recourse factoring may not dominate

(2) For $\alpha>\left.\Pi_{2}^{m}\right|_{q_{2}=q_{2}^{*}}$, when $\lambda \leq \bar{\lambda}$, recourse factoring is still the optimal scheme; however, when $\lambda>\bar{\lambda}$, nonrecourse factoring may not dominate

In the cases one factoring scheme loses its dominance, we can always find feasible interval of $\beta$ and the corresponding threshold of $\alpha$ that cause the other one to be more favorable to the supplier.

The above analysis shows that when the risk constraint is considered, both of the two factoring schemes have their superiorities. While nonrecourse factoring guarantees a least profit that may satisfy the supplier's target profit, recourse factoring can reach a higher production level when $q_{i}^{*}$ is unrealizable $\left(\widehat{q}_{1}>\widehat{q}_{2}\right)$. Proposition 4 shows the cases where their superiorities enable them to be the dominant factoring arrangements. Next, Figure 2 plots the supplier's global optimal strategies under various risk constraints.

If the target profit of the supplier is small, that is, $\alpha \leq\left.\Pi_{2}^{m}\right|_{q_{2}=q_{2}^{*}}$, nonrecourse factoring's superiority is key, and it would be chosen even if $\lambda$ is relatively small (see Figure 2(a)). $\hat{q}_{1}$ is dominated by $q_{2}^{*}$ in the shaded area, where $\beta$ is below the boundary (the solution of $\left.\Pi_{1}\right|_{q_{1}=\widehat{q}}=\Pi_{2}^{*}$ ). Such a result represents the case when the supplier tends to avoid the "extreme disaster." When market demand fluctuation is huge and the current deal makes up a large proportion of the supplier's business, the supplier's survival will be threatened once the demand realized is extremely low; in this situation, the supplier should choose nonrecourse factoring to gain part of assured profit.

If the target profit of the supplier is large, that is, $\alpha>\left.\prod_{2}^{m}\right|_{q_{2}=q_{2}^{*}}$, recourse factoring's superiority is key, and it would be chosen even if $\lambda$ is relatively large (see Figures 2(b) and 2(c)). Since the target profit is larger, in these cases, the supplier actually prefers a more profitable production plan; at the same time, he has to assure the risk under control. Then, the supplier will choose recourse factoring, because it permits a higher risk upper limit. Moreover, when $r_{2}$ becomes smaller, the chance that nonrecourse factoring is dominated by recourse one gets lower. That means when the supplier is able to obtain a generous and cheap financing from the factor without recourse, his expected profit is so high that even the risk constraint prevents him from producing more; his profit may still exceed the case with recourse factoring.

6.3. The Benefits of Factoring Finance for a Risk Averse Supplier. Since there are lots of parameters and variables in our model, we only get some general ideas about how factoring finance affects the supplier's operational strategies and their results. In this part, we will discuss the benefits of factoring to the supplier numerically to obtain some other useful points. As the risk-neutral supplier case is very simple, we focus on the risk-averse supplier case in this section. Let $c=0.5, r_{0} / r_{2} / r_{1}=0.15 / 0.13 / 0.1, m / M=$ $0.1 / 0.4, \lambda=0.7$, and $\beta=0.1$. After calculation, we find that when the target profit $\alpha$ is higher than a certain level (say 0.6 here), the supplier's production quantity decisions in all financing schemes are bounded by the risk constraint except for nonrecourse factoring in some cases. The exception exists because of the factor's credit guarantee function; that is, the supplier does not have to repay the cash received in advance. The dependence of the supplier's maximum expected profit on his risk attitudes appears in Figure 3.

To capture the account receivable management benefit of factoring for the supplier, we add one benchmark where the financing ratio is supposed to be 0 . Then, from Figure 3, $\left.\max \Pi_{1}\right|_{\lambda=0}$ exceeds $\max \Pi_{0}$ when $\alpha$ is less than 1.47, which attributes to the larger feasible production amount (discussed in Lemma 3). We regard the positive balance between $\left.\max \Pi_{1}\right|_{\lambda=0}$ and $\max \Pi_{0}$ as the accounts receivable management benefit of factoring. Figure 3 illustrates that, with the increase of $\alpha$, this benefit gets smaller until it disappears finally; that is because the upper boundary of the supplier's production under factoring finance is higher than no factoring case only when it is relatively large. Therefore, when the target profit is too high (resulting in a small upper boundary), the supplier cannot obtain such benefit, causing the factoring finance to be not attractive anymore. The financial benefit of factoring is got by increasing $\lambda$ from 0 to 0.7 , and it is not very sensitive to the change of the supplier's risk attitude. Thus, providing enough advanced payment always helps to make the supplier accept factoring, no matter how his risk attitude changes. The guarantee benefit in Figure 3 is the positive balance between $\max \Pi_{2}$ and $\max \Pi_{1}$. When $\alpha$ is smaller than a certain level, we can see a great enhancement of the supplier's expected profit, and the higher $\alpha$ is the more extra guarantee benefit the supplier can get. However, once the target profit exceeds the threshold $\left.\Pi_{2}^{m}\right|_{q_{2}=q_{2}^{*}}$, the guarantee benefit disappears. 

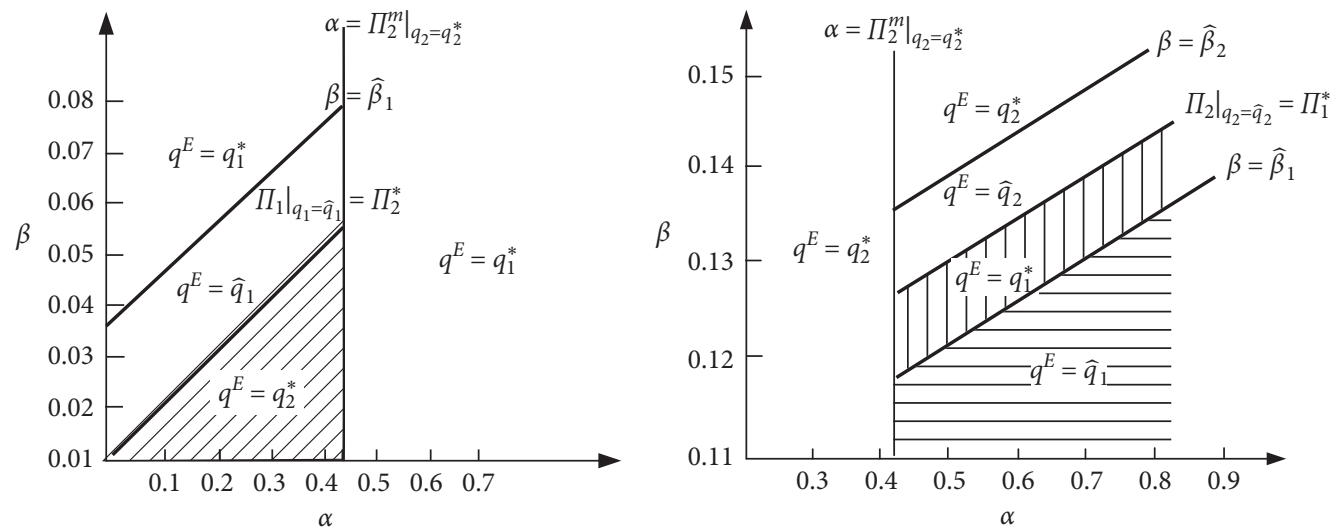

$$
\begin{aligned}
& M=0.75 \\
& \lambda=0.7 \\
& r_{2}=0.138
\end{aligned}
$$

$$
\begin{aligned}
& M=0.45 \\
& \lambda=0.8 \\
& r_{2}=0.138
\end{aligned}
$$

(a)

(b)

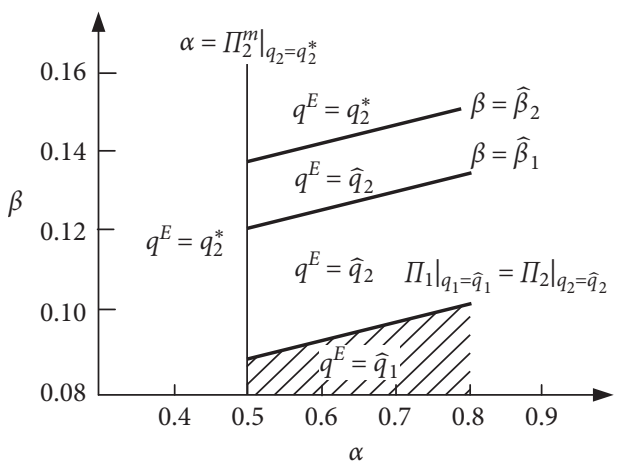

$$
\begin{aligned}
& M=0.45 \\
& \lambda=0.8 \\
& r_{2}=0.12
\end{aligned}
$$

(c)

FIGURE 2: A risk-averse supplier's optimal production decisions with various risk attitudes.

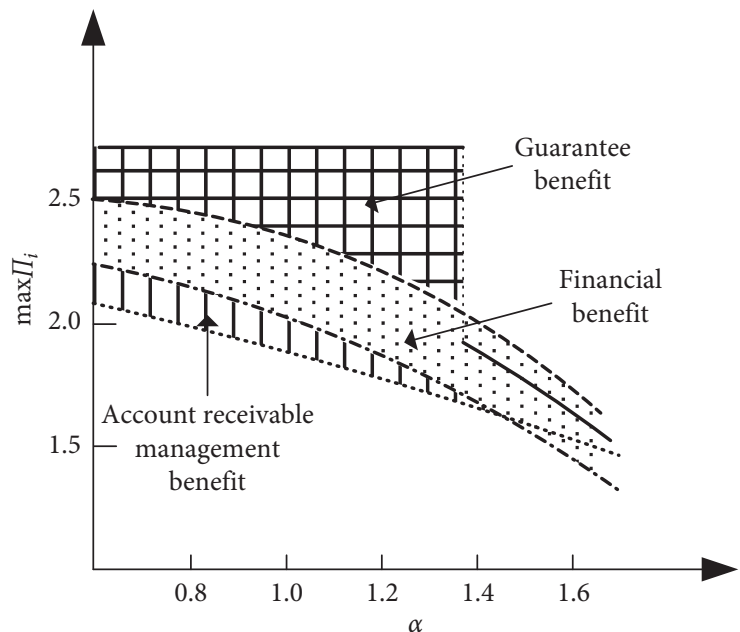

Uniform distribution $(0,40)$

$\begin{array}{ll}\cdots \cdots \cdot \max \Pi_{0} & \text {-.- } \max \Pi_{1} \\ -\max \Pi_{2} & \text {-.-. }\left.\max \Pi_{1}\right|_{\lambda=0}\end{array}$

FIgURE 3: The maximum expected profits of the supplier with different target profits. 


\section{Conclusions}

In this paper, we present a supply chain factoring finance model that accounts for the factor's comparative advantage in managing the accounts receivable and monitoring the debtor. We want to find out the benefits of factoring finance to a supplier and how he chooses between recourse factoring and nonrecourse factoring. After introducing the effect of receivables management on the player's expected profit, we obtain the Stackelberg equilibrium in the strategic interaction between the supplier and retailer when different financing arrangements are adopted and find the conditions under which a specific factoring scheme is preferred by the supplier.

We first examine the supplier's pricing strategy and the retailer's ordering decision when no factoring is involved as a benchmark, which enables us to derive the preconditions that make factoring contract acceptable in terms of $\lambda$ and $r_{1}$ (or $r_{2}$ ). Then, by comparing the Stackelberg equilibrium solutions of a risk-neutral supplier under recourse factoring and nonrecourse factoring, we find that the supplier's choice between the two factoring schemes depends on a threshold of the factoring finance ratio. If the finance ratio provided by the factor is higher than that threshold, then the supplier's expected profit will be larger when he chooses nonrecourse factoring. Otherwise, the supplier should choose recourse factoring.

Finally, we extend our models by considering the supplier's risk attitude and show that the risk-averse supplier's factoring decision depends not only on the factoring finance ratio $\lambda$ but also on the supplier's risk averseness. When setting a larger target profit, the supplier may choose nonrecourse factoring when $\lambda$ is lower than the threshold; otherwise, he may choose recourse factoring when $\lambda$ is higher than the threshold. Furthermore, we identify the three benefits the supplier can obtain from factoring: receivables management benefit, financial benefit, and guarantee benefit.

\section{Appendix}

\section{Proof of Proposition 1}

(a) By differentiating $\pi_{0}$ with respect to $q_{0}$ and collecting terms, we have $d \pi_{0} / d q_{0}=\bar{F} \quad\left(q_{0}\right)-(1-m) w_{0} \bar{F}$ $\left(w_{0} q_{0}\right)-m w_{0}$. Then, the optimal $q_{0}^{*}$ satisfies the first-order condition $\bar{F}\left(q_{0}^{*}\right)=(1-m) w_{0} \bar{F}\left(w_{0} q_{0}^{*}\right)+$ $m w_{0}$. Moreover, $d^{2} \pi_{0} /\left.d\left(q_{0}\right)^{2}\right|_{q_{0}=q_{0}^{*}}=-f\left(q_{0}^{*}\right)+(1-$ m) $w_{0} f\left(w_{0} q_{0}^{*}\right) \quad w_{0} \leq \bar{F}\left(q_{0}^{*}\right)\left[-h\left(q_{0}^{*}\right)+w_{0} h\left(w_{0} q_{0}^{*}\right)\right]<0$; the last inequality holds because of the IFR (increasing failure rate) assumption. Thus, $q_{0}^{*}$ is unique and is the optimal decision of the retailer

(b) From equation (2), $\mathrm{d} q_{0}^{*} / \mathrm{d} m=w_{0} F\left(w_{0} q_{0}^{*}\right) /$ $\left(-f\left(q_{0}^{*}\right)+(1-m) w_{0} f\left(w_{0} q_{0}^{*}\right) w_{0}\right)<0$; therefore, $q_{0}^{*}$ decreases in $m$. When $m=0$, the retailer's first-order condition can be written as $\bar{F}\left(q_{0}^{*}\right)=w_{0} \bar{F}\left(w_{0} q_{0}^{*}\right)$. Since $x \bar{F}(x)$ is a convex function of $x$ and reaches its top at $H(x)=1$, let $\widetilde{q}$ solve $H(\widetilde{q})=1$; we can get that $q_{0}^{*} \geq \widetilde{q}$ and $w_{0} q_{0}^{*}<\widetilde{q}$ for any given $w_{0} \in[c, 1]$ in this situation. In particular, $q_{0}^{*}=\widetilde{q}$ in the case $w_{0}=1$. Then, for any $m \in(0,1), w_{0} q_{0}^{*}$ is always smaller than $\tilde{q}$; that is, $1-H\left(w_{0} q_{0}^{*}\right)>0$. Thus, $d q_{0}^{*} / d w_{0}=[(1-$ $\left.m) \bar{F}\left(w_{0} q_{0}^{*}\right)\left(1-H\left(w_{0} q_{0}^{*}\right)\right)+m\right] /\left(-f\left(q_{0}^{*}\right)+(1-m)\right.$ $\left.w_{0} f\left(w_{0} q_{0}^{*}\right) w_{0}\right)<0$

(c) Because $q_{0}^{*}$ decreases in $m$, it is obvious that $\left.q_{0}^{*}\right|_{w_{0}=1}<\widetilde{q}$ for any $m \in(0,1)$. Recall that $q_{0}^{*}$ is a monotone decreasing function of $w_{0}$; there is at most one $\widetilde{w}_{0}$ satisfying $q_{0}^{*}\left(\widetilde{w}_{0}\right)=\widetilde{q}$. Since $d\left(w_{0} q_{0}^{*}\right) / d w_{0}=$ $\left[\bar{F}\left(q_{0}^{*}\right)\left(1-H\left(q_{0}^{*}\right)\right)\right] /\left(-f\left(q_{0}^{*}\right)+(1-m) w_{0} f\left(w_{0} q_{0}^{*}\right)\right.$ $\left.w_{0}\right)<0$, we can obtain how $w_{0} q_{0}^{*}$ changes with $w_{0}$ in Proposition 1.

Proof of Proposition 2. Take the first-order derivative of $\Pi_{0}$ with respect to $w_{0}$; we have

$$
\begin{aligned}
\frac{\mathrm{d} \Pi_{0}}{\mathrm{~d} w_{0}}= & -\frac{c\left(1+r_{0}\right)\left[(1-m) \bar{F}\left(w_{0} q_{0}^{*}\right)\left(1-H\left(w_{0} q_{0}^{*}\right)\right)+m\right]}{-f\left(q_{0}^{*}\right)+(1-m) w_{0} f\left(w_{0} q_{0}^{*}\right) w_{0}} \\
& \cdot\left[1-\frac{1}{c\left(1+r_{0}\right)} \frac{\left[(1-m) \bar{F}\left(w_{0} q_{0}^{*}\right)+m\right] \bar{F}\left(q_{0}^{*}\right)\left(1-H\left(q_{0}^{*}\right)\right)}{(1-m) \bar{F}\left(w_{0} q_{0}^{*}\right)\left[1-H\left(w_{0} q_{0}^{*}\right)\right]+m}\right] .
\end{aligned}
$$

Let

$$
\eta_{0}\left(w_{0}\right)=\frac{1}{c\left(1+r_{0}\right)} \frac{\left[(1-m) \bar{F}\left(w_{0} q_{0}^{*}\right)+m\right] \bar{F}\left(q_{0}^{*}\right)\left(1-H\left(q_{0}^{*}\right)\right)}{(1-m) \bar{F}\left(w_{0} q_{0}^{*}\right)\left[1-H\left(w_{0} q_{0}^{*}\right)\right]+m}
$$

To show that $\Pi_{0}$ is a unimodal function and reaches its maximum when the first-order derivative is 0 , we only have to prove that $\eta_{0}\left(w_{0}\right)$ increases in $w_{0}$; that is, the optimal wholesale price $w_{0}^{*}$ must be the one that makes $\eta_{0}\left(w_{0}^{*}\right)=1$.
Let $K^{1}=(1-m) \bar{F}\left(w_{0} q_{0}^{*}\right)+m, \quad K^{2}=\bar{F}\left(q_{0}^{*}\right)\left[1-H\left(q_{0}^{*}\right)\right]$, and $\quad K^{3}=(1-m) \bar{F}\left(w_{0} q_{0}^{*}\right)\left[1-H\left(w_{0} q_{0}^{*}\right)\right]+m$; then $\mathrm{d} \eta_{0}\left(w_{0}\right) / \mathrm{d} w_{0}$ equals $K_{w_{0}}^{1} K^{2} K^{3}+K^{1} K_{w_{0}}^{2} K^{3}-K^{1} K^{2} K_{w_{0}}^{3}$, where 


$$
\begin{aligned}
K_{w_{0}}^{1}= & {\left[-(1-m) f\left(w_{0} q_{0}^{*}\right)\right] \frac{\mathrm{d}\left(w_{0} q_{0}^{*}\right)}{\mathrm{d} w_{0}}, } \\
K_{w_{0}}^{2}= & {\left[-f\left(q_{0}^{*}\right)\left(1-H\left(q_{0}^{*}\right)\right)-\bar{F}\left(q_{0}^{*}\right) H^{\prime}\left(q_{0}^{*}\right)\right] \frac{\mathrm{d} q_{0}^{*}}{\mathrm{~d} w_{0}}, } \\
K_{w_{0}}^{3}= & {\left[-f\left(w_{0} q_{0}^{*}\right)\left(1-H\left(w_{0} q_{0}^{*}\right)\right)-\bar{F}\left(w_{0} q_{0}^{*}\right) H^{\prime}\left(w_{0} q_{0}^{*}\right)\right] } \\
& \cdot \frac{\mathrm{d}\left(w_{0} q_{0}^{*}\right)}{\mathrm{d} w_{0}} .
\end{aligned}
$$

Obviously, $K_{w_{0}}^{1} K^{2} K^{3}>0$. Recall that $\left|\mathrm{d} q_{0}^{*} / \mathrm{d} w_{0}\right|>$ $\left|\mathrm{d}\left(w_{0} q_{0}^{*}\right) / \mathrm{d} w_{0}\right|$ and $K^{3}>K^{2}$; by extracting common factors $\bar{F}\left(q_{0}^{*}\right)\left[1-H\left(q_{0}^{*}\right)\right]$ and $\bar{F}\left(w_{0} q_{0}^{*}\right)\left[1-H\left(w_{0} q_{0}^{*}\right)\right]$ from $K_{w_{0}}^{2}$ and $K_{w_{0}}^{3}$, respectively, we can easily get $K^{1} K_{w_{0}}^{2} K^{3}-$ $K^{1} K^{2} K_{w_{0}}^{3}>0$. Thus, $\eta_{0}\left(w_{0}\right)$ increases in $w_{0}$ monotonously, and $\mathrm{d} \Pi_{0} / \mathrm{d} w_{0}=0$ when $\eta_{0}\left(w_{0}\right)=1$.

Proof of Lemma 1. To prove the lemma, we just have to find out the cases when $\Pi_{1}^{*}>\Pi_{0}^{*}$. Firstly, we simplify the supplier's expected profit into

$$
\begin{aligned}
\Pi_{1}^{*}= & \int_{0}^{w_{1}^{*} q_{1}^{*}}(1-M) \bar{F}(D) d D+M w_{1}^{*} q_{1}^{*} \\
& +\left(\frac{1+r_{0}}{1+r_{1}}-1\right) \lambda w_{1}^{*} q_{1}^{*}-c q_{1}^{*}\left(1+r_{0}\right) .
\end{aligned}
$$

Consider the case $\lambda=0$; it is easy to have

$$
\begin{aligned}
\frac{\mathrm{d} \Pi_{1}^{*}}{\mathrm{~d} M}= & -\int_{0}^{w_{1}^{*} q_{1}^{*}} \bar{F}(D) d D+(1-M) \bar{F}\left(w_{1}^{*} q_{1}^{*}\right) \frac{\mathrm{d}\left(w_{1}^{*} q_{1}^{*}\right)}{\mathrm{d} M} \\
& +w_{1}^{*} q_{1}^{*}+M \frac{\mathrm{d}\left(w_{1}^{*} q_{1}^{*}\right)}{\mathrm{d} M}-c\left(1+r_{0}\right) \frac{\mathrm{d} q_{1}^{*}}{\mathrm{~d} M} .
\end{aligned}
$$

From equation (7),

$$
\begin{aligned}
\frac{\mathrm{d} q_{1}^{*}}{\mathrm{~d} M}= & \frac{(1-M)\left[\bar{F}\left(w_{1}^{*} q_{1}^{*}\right)-w_{1}^{*} q_{1}^{*} f\left(w_{1}^{*} q_{1}^{*}\right)\right]+M}{\bar{F}\left(q_{1}^{*}\right)-q_{1}^{*} f\left(q_{1}^{*}\right)} \frac{\mathrm{d}\left(w_{1}^{*} q_{1}^{*}\right)}{\mathrm{d} M} \\
& +\frac{w_{1}^{*} q_{1}^{*} F\left(w_{1}^{*} q_{1}^{*}\right)}{\bar{F}\left(q_{1}^{*}\right)-q_{1}^{*} f\left(q_{1}^{*}\right)}
\end{aligned}
$$

and then $\mathrm{d} \Pi_{1}^{*} / \mathrm{d} M$ can be organized as

$$
\int_{0}^{w_{1}^{*} q_{1}^{*}} F(D) \mathrm{d} D-c\left(1+r_{0}\right) \frac{w_{1}^{*} q_{1}^{*} F\left(w_{1}^{*} q_{1}^{*}\right)}{\bar{F}\left(q_{1}^{*}\right)-q_{1}^{*} f\left(q_{1}^{*}\right)}<0 .
$$

The inequality holds because $c\left(1+r_{0}\right) /\left(\bar{F}\left(q_{1}^{*}\right)-\right.$ $\left.q_{1}^{*} f\left(q_{1}^{*}\right)\right)>1$ (which follows equation (7) directly). Thus, $\Pi_{1}^{*}$ decreases in $M$ in this case, which means that $\Pi_{1}^{*}$ cannot exceed $\Pi_{0}^{*}$ when $\lambda=0$. If $\lambda>0$, using similar method, we find that $\Pi_{1}^{*}$ decreases in $r_{1}$ and increases in $\lambda$ monotonously and reaches its maximum at $r_{1}=0$ and $\lambda=1$. To focus only on the interesting cases, we omit the cases when
$\left.\Pi_{1}^{*}\right|_{r_{1}=0, \lambda=1} \leq \Pi_{0}^{*}$; then we may always make recourse factoring contract acceptable by adjusting $r_{1}$ and $\lambda$.

Proof of Proposition 3. From equations (9) and (6), $\mathrm{d} \Pi_{2}^{*} / \mathrm{d} \lambda=$ $\left[(1-M) F\left(\lambda w_{2}^{*} q_{2}^{*}\right)+\left(\left(1+r_{0}\right) /\left(1+r_{2}\right)-1\right)\right] w_{2}^{*} q_{2}^{*}$ and $\mathrm{d} \Pi_{1}^{*} /$ $\mathrm{d} \lambda=\left(\left(1+r_{0}\right) /\left(1+r_{1}\right)-1\right) w_{1}^{*} q_{1}^{*}$. Define $\lambda$ satisfying $(1-$ M)F $\left(\lambda w_{2}^{*} q_{2}^{*}\right)+\left(\left(1+r_{0}\right) /\left(1+r_{2}\right)-1\right)=\left(1+r_{0}\right) /\left(1+r_{1}\right)-$ 1 as $\underline{\lambda} ; \underline{\lambda}$ is unique because of the monotonous increasing of $(1-\bar{M}) F\left(\lambda w_{2}^{*} q_{2}^{*}\right)$ in $\lambda$. Moreover, when $\lambda=\underline{\lambda}, w_{1}^{*} q_{1}^{*}=w_{2}^{*} q_{2}^{*}$ holds. Thus, in the case $\lambda \leq \underline{\lambda}, \mathrm{d} \Pi_{2}^{*} / \mathrm{d} \lambda<\mathrm{d} \Pi_{1}^{*} / \mathrm{d} \lambda$. Note that $\left.\Pi_{2}^{*}\right|_{\lambda=0}=\left.\Pi_{1}^{*}\right|_{\lambda=0}$; then $\Pi_{2}^{*}<\Pi_{1}^{*}$ at $\underline{\lambda}$. When $\underline{\lambda}<\lambda \leq 1$, $\mathrm{d} \Pi_{2}^{*} / \mathrm{d} \lambda>\mathrm{d} \Pi_{1}^{*} / \mathrm{d} \lambda$. Since we assume that the nonrecourse factoring fee satisfies $\left.\Pi_{2}^{*}\right|_{\lambda=1}>\left.\Pi_{1}^{*}\right|_{\lambda=1}$, there must exist $\bar{\lambda}$ that makes $\Pi_{2}^{*}=\Pi_{1}^{*}$, and the conclusions in Proposition 3 follow.

Proof of Lemma 2. In the nonrecourse factoring scenario, the factor gets $D$ with probability $1-M$ and gets $\lambda w_{2} q_{2}$ with probability $M$ when the market demand is lower than $\lambda w_{2} q_{2}$ and gets $\lambda w_{2} q_{2}$ otherwise. Hence, the factor's expected profit given that the supplier and retailer choose their optimal decisions $w_{2}^{*}$ and $q_{2}^{*}$ can be expressed as $\Pi_{F 2}^{*}=\int_{0}^{\lambda w_{2}^{*} q_{2}^{*}}$ $(1-M) \bar{F}(D) d D+M \lambda w_{2}^{*} q_{2}^{*}-\lambda w_{2}^{*} q_{2}^{*} /\left(1+r_{2}\right)$. Then, it is easy to find that $\Pi_{F 2}^{*}$ is always nonnegative when $r_{2} \geq(1 / M)-1$. In the case $r_{2}<(1 / M)-1, \Pi_{F 2}^{*}$ can be seen as a function of $\lambda w_{2}^{*} q_{2}^{*}$ with the first-order derivative as (1$M) \bar{F}\left(\lambda w_{2}^{*} q_{2}^{*}\right)+M-1 /\left(1+r_{2}\right)$ and the second-order derivative as $-(1-M) f\left(\lambda w_{2}^{*} q_{2}^{*}\right)$. That means $\Pi_{F 2}^{*}$ is a concave function of $w_{2}^{*} q_{2}^{*}$ when $\lambda$ is given. Note that $\Pi_{F 2}^{*}$ is equal to 0 and with positive first-order derivative when $w_{2}^{*} q_{2}^{*}=0$. Then, if $w_{2}^{*} q_{2}^{*}$ is not too big (smaller than the other $w_{2}^{*} q_{2}^{*}$ that makes $\Pi_{F 2}^{*}=0$ besides 0$), \Pi_{F 2}^{*}$ will always be positive. Thus, we can prove the lemma by showing that $w_{2}^{*} q_{2}^{*}$ decreases in $r_{0}$. Let $K^{4}=(1-M) \bar{F}\left(w_{2}^{*} q_{2}^{*}\right)\left[1-H\left(w_{2}^{*} q_{2}^{*}\right)\right]+M \quad$ and $K^{5}=\bar{F}\left(q_{2}^{*}\right)\left[1-H\left(q_{2}^{*}\right)\right]$. Adopt implicit function derivation to the retailer's and the supplier's first-order conditions; we have $\mathrm{d} q_{2}^{*} / \mathrm{d} r_{0}=\left(K^{4} / K^{5}\right)\left(\mathrm{d}\left(w_{2}^{*} q_{2}^{*}\right) / \mathrm{d} r_{0}\right)$ and

$$
\begin{aligned}
& (1-M)\left[-f\left(w_{2}^{*} q_{2}^{*}\right)+\lambda^{2} f\left(\lambda w_{2}^{*} q_{2}^{*}\right)\right] \frac{\mathrm{d}\left(w_{2}^{*} q_{2}^{*}\right)}{\mathrm{d} r_{0}} \\
& =c\left(1+r_{0}\right)\left[\frac{K_{w_{2}^{*} q_{2}^{*}}^{4}}{K^{5}} \frac{\mathrm{d}\left(w_{2}^{*} q_{2}^{*}\right)}{\mathrm{d} r_{0}}-\frac{K^{4} K_{q_{2}^{*}}^{5}}{\left(K^{5}\right)^{2}} \frac{\mathrm{d} q_{2}^{*}}{\mathrm{~d} r_{0}}\right]+c \frac{K^{4}}{K^{5}}-\frac{\lambda}{1+r_{2}} \text {. }
\end{aligned}
$$

The item $-f\left(w_{2}^{*} q_{2}^{*}\right)+\lambda^{2} f\left(\lambda w_{2}^{*} q_{2}^{*}\right)<0$ follows from the fact that

$$
w_{2}^{*} q_{2}^{*} \bar{F}\left(w_{2}^{*} q_{2}^{*}\right) h\left(w_{2}^{*} q_{2}^{*}\right)>\lambda w_{2}^{*} q_{2}^{*} \bar{F}\left(\lambda w_{2}^{*} q_{2}^{*}\right) h\left(\lambda w_{2}^{*} q_{2}^{*}\right)
$$

$H\left(w_{2}^{*} q_{2}^{*}\right)<1$; and $\left(K_{w_{2}^{*} q_{2}^{*}}^{4} / K^{5}\right)-\left(K^{4} K_{q_{2}^{*}}^{5} /\left(K^{5}\right)^{2}\right)\left(K^{4} / K^{5}\right)>0$ can be proven similar to the proof of Proposition 2. Thus, $\mathrm{d}\left(w_{2}^{*} q_{2}^{*}\right) / \mathrm{d} r_{0}<0$ holds all the time; that is, for a given $r_{2}$, the factor can be at least break-even when $r_{0}$ is relatively large. Since $\bar{r}_{2}$ is a function of $r_{0}$ and $r_{1}$, we can always find the nonrecourse factoring service fees that are acceptable to both the supplier and the factor by changing $r_{0}$ and $r_{1}$ simultaneously. 
Proof of Lemma 3. Remember that, for brevity, we denote $w_{i} q_{i}$ by $z_{i}$. Since for any given $q_{0}$, the supplier's profit is $(1-m) D+m z_{0}-c q_{0}\left(1+r_{0}\right)$, the risk constraint can be expressed as $P\left\{(1-m) D+m z_{0}-c q_{0}\left(1+r_{0}\right) \leq \alpha\right\} \leq \beta$, which is equivalent to $\left(\alpha+c q_{0}\left(1+r_{0}\right)-m z_{0}\right) /(1-m) \leq$ $F^{-1}(\beta)$. By analyzing the first-order and second-order derivative of $\left(\alpha+c q_{0}\left(1+r_{0}\right)-m z_{0}\right) /(1-m)$, we can see that it is a concave function of $q_{0}$. Therefore, if $F^{-1}(\beta)$ is higher than the minimum, there exist two $q_{0}$ that make $\left(\alpha+c q_{0}\left(1+r_{0}\right)-m z_{0}\right) /(1-m)=F^{-1}(\beta)$. Compared with $q_{0}^{*}$, it is easy to find that the one with positive first-order derivative is $\widehat{q}_{0}$. From $\alpha+c \widehat{q}_{0}\left(1+r_{0}\right)-m \widehat{z}_{0}=(1-m)$ $F^{-1}(\beta)$ and $(2)$, we have

$$
\begin{aligned}
& c\left(1+r_{0}\right) \frac{\mathrm{d} \widehat{q}_{0}}{\mathrm{~d} m}-m \frac{\bar{F}\left(\widehat{q}_{0}\right)-\widehat{q}_{0} f\left(\widehat{q}_{0}\right)}{(1-m)\left[\bar{F}\left(\widehat{z}_{0}\right)-\widehat{z}_{0} f\left(\widehat{z}_{0}\right)\right]+m} \frac{\mathrm{d} \widehat{q}_{0}}{\mathrm{~d} m}+m \frac{\widehat{z}_{0} F\left(\widehat{z}_{0}\right)}{(1-m)\left[\bar{F}\left(\widehat{z}_{0}\right)-\widehat{z}_{0} f\left(\widehat{z}_{0}\right)\right]+m}=\widehat{z}_{0}-F^{-1}(\beta) \\
& \cdot\left[c\left(1+r_{0}\right)-m \frac{\bar{F}\left(\widehat{q}_{0}\right)-\widehat{q}_{0} f\left(\widehat{q}_{0}\right)}{(1-m)\left[\bar{F}\left(\widehat{z}_{0}\right)-\widehat{z}_{0} f\left(\widehat{z}_{0}\right)\right]+m}\right] \frac{\mathrm{d} \widehat{q}_{0}}{\mathrm{~d} m}=\frac{(1-m)\left[\bar{F}\left(\widehat{z}_{0}\right)-\widehat{z}_{0} f\left(\widehat{z}_{0}\right)\right]\left[\widehat{z}_{0}-F^{-1}(\beta)\right]+m \widehat{z}_{0} \bar{F}\left(\widehat{z}_{0}\right)-m \bar{F}-1(\beta)}{(1-m)\left[\bar{F}\left(\widehat{z}_{0}\right)-\widehat{z}_{0} F\left(\widehat{z}_{0}\right)\right]+m} .
\end{aligned}
$$

Thus, if $\widehat{z}_{0} \bar{F}\left(\widehat{z}_{0}\right)>F^{-1}(\beta)$, we have $\mathrm{d} \widehat{q}_{0} / \mathrm{d} m>0$.

Proof of Lemma 4. Define $T$ as the discrepancy of $\Pi_{2}$ and $\Pi_{1}$ at any given production quantity $q$; that is,

$$
\begin{aligned}
T=\Pi_{2}-\Pi_{1} & =\int_{0}^{\lambda w q}(1-M) F(D) d D-\left(\frac{1+r_{0}}{1+r_{1}}-\frac{1+r_{0}}{1+r_{2}}\right) \lambda w q \\
& =\lambda w q\left[\frac{\int_{0}^{\lambda w q}(1-M) F(D) \mathrm{d} D}{\lambda w q}-\left(\frac{1+r_{0}}{1+r_{1}}-\frac{1+r_{0}}{1+r_{2}}\right)\right] .
\end{aligned}
$$

Since $\int_{0}^{\lambda w q}(1-M) F(D) \mathrm{d} D / \lambda w q$ increases in $\lambda w q$, there is only one $\lambda w q$ that makes $T=0$. Thus, for any $\lambda$, there exits only one $w q$ (or equivalently $q$ ) that solves $\Pi_{2}-\Pi_{1}=0$, which we denote as $q^{\#}$. Obviously, $q^{\#}$ decreases in $\lambda$.

As shown in the proof of Proposition 3 , when $\lambda=\underline{\lambda}$ we have $q_{1}^{*}=q_{2}^{*}$ and $(1-M) F\left(\lambda w_{2}^{*} q_{2}^{*}\right)=\left(1+r_{0}\right) /\left(1+r_{1}\right)-$ $\left(1+r_{0}\right) /\left(1+r_{2}\right)$. Notice that

$$
(1-M) F(\lambda w q) \geq \frac{\int_{0}^{\lambda w q}(1-M) F(D) \mathrm{d} D}{\lambda w q},
$$

and $q_{1}^{*}=q_{2}^{*}<q^{\#}$ always holds when $\lambda=\underline{\lambda}$. Moreover, with the increase of $\lambda$, both $q_{1}^{*}$ and $q_{2}^{*}$ increase (this can be simply proven by adopting implicit function derivation to the retailer's and the supplier's first-order condition and the proof is omitted here) and $q_{2}^{*}$ remains larger than $q_{1}^{*}$. Recall that $q^{\#}$ decreases in $\lambda$; then $\lambda_{1}$ and $\lambda_{2}$ must exist and $\lambda_{2} \leq \lambda_{1}$.

Finally, we prove the comparison among $\lambda_{1}, \lambda_{2}$, and $\bar{\lambda}$ by contradiction. Suppose that $\bar{\lambda}<\lambda_{2}$; then $\Pi_{1}^{*}=\Pi_{2}^{*}$ and $q_{1}^{*}<q_{2}^{*}<q^{\#}$ hold simultaneously when $\lambda=\bar{\lambda}$. In this case, the supplier's expected profit increases from $\left.\Pi_{2}\right|_{q=q_{1}^{*}}$ to $\Pi_{2}^{*}$ in the interval $\left[q_{1}^{*}, q_{2}^{*}\right]$, while $\Pi_{1}$ decreases from $\Pi_{2}^{*}$ to $\left.\Pi_{1}\right|_{q=q_{2}^{*}}$. Consequently, there is a $q \in\left[q_{1}^{*}, q_{2}^{*}\right]$ that makes $\Pi_{1}=\Pi_{2}$, which contradicts to $q_{1}^{*}<q_{2}^{*}<q^{\#}$, since there is only one $q$ that solves $\Pi_{2}-\Pi_{1}=0$. Thus, $\lambda_{2} \leq \bar{\lambda}$ always holds. Similarly, we have $\lambda_{1} \geq \bar{\lambda}$. The same analysis can be done to $\underline{\lambda}$.
From the above analysis, we can easily obtain the comparison of $q^{\#}, q_{1}^{*}$, and $q_{2}^{*}$ when $\lambda$ has different values.

Proof of Proposition 4. According to the possible comparisons of $\Pi_{1}^{*}$ and $\Pi_{2}^{*}$ and $q_{1}^{*}$ and $q_{2}^{*}$ discussed before, we have the contrast between $\Pi_{1}$ and $\Pi_{2}$ when different production quantities are chosen (we suggest readers to draw the curves of $\Pi_{i}$ to understand the following analysis).

(1) As shown before, when $\alpha \leq\left.\Pi_{2}^{m}\right|_{q_{2}=q_{2}^{*}}, q_{2}^{*}$ will never be constrained by the risk condition; nonrecourse factoring is still dominant when $\lambda>\bar{\lambda}$. In the case $\lambda \leq \bar{\lambda}$, that is, $\Pi_{1}^{*}>\Pi_{2}^{*}$ if, $\beta>\widehat{\beta}_{1}$, then $q_{1}^{*}$ also meets the risk constraint and thus is dominant; otherwise, the supplier receives the highest profit at $\hat{q}_{1}$ when choosing recourse factoring. Since both $\widehat{q}_{1}$ and $\left.\Pi_{1}\right|_{q_{1}=\widehat{q}_{1}}$ decrease in $\alpha$ (this can be proven by implicit function differentiation and is omitted here), there must exist a unique $\alpha$ such that $\left.\Pi_{1}\right|_{q_{1}=\widehat{q}_{1}}=\Pi_{2}^{*}$. If the unique $\alpha$ is also smaller than, $\left.\Pi_{2}^{m}\right|_{q_{2}=q_{2}^{*}}$ then it is the critical point that the supplier's optimal strategy switches.

(2) When $\alpha>\left.\Pi_{2}^{m}\right|_{q_{2}=q_{2}^{*}}$, both $q_{1}^{*}$ and $q_{2}^{*}$ may not meet the risk constraints. In the case $\lambda \leq \bar{\lambda}$, if $q_{1}^{*}>\widehat{q}_{1}$, then the supplier will definitely choose recourse; otherwise, as $\hat{q}_{1}>\hat{q}_{2}$, the supplier using nonrecourse factoring must choose a production quantity $\left(q_{2}\right.$ either $\widehat{q}_{1}$ or $\left.q_{2}^{*}\right)$ that is smaller than $\widehat{q}_{1}$, causing $\Pi_{2}<\left.\Pi_{1}\right|_{q_{1}=\widehat{q}_{1}}$. Hence, recourse factoring is always dominant. In the case $\lambda>\bar{\lambda}$, if $\widehat{\beta}_{1} \leq \beta \leq \widehat{\beta}_{2}$, that is, $q_{1}^{*}<\widehat{q}_{1}$ and $q_{2}^{*}>\widehat{q}_{2}$, there must exist a unique $\alpha$ such that $\left.\Pi_{2}\right|_{q_{2}=\widehat{q}_{2}}=\Pi_{1}^{*}$; if $\beta \leq \widehat{\beta}_{1}$, that is $q_{1}^{*}>\widehat{q}_{1}$ and $q_{2}^{*}>\widehat{q}_{2}$, we can find a unique $\alpha$ such that $\hat{q}_{2}=q^{\#}$ ( $\alpha$ being larger than this threshold is an adequate but not necessary condition to guarantee $\left.\Pi_{1}\right|_{q_{1}=\widehat{q}_{1}}>\left.\Pi_{2}\right|_{q_{2}=\widehat{q}_{2}}$ ). If these thresholds are also larger than $\left.\Pi_{2}^{m}\right|_{q_{2}=q_{2}^{*}}$ then the supplier's optimal financial changes at this point. 


\section{Data Availability}

All the models and proofs appear in the submitted article. In this article, no other data or codes were generated or used during the study.

\section{Conflicts of Interest}

The authors declare that they have no conflicts of interest.

\section{Acknowledgments}

This paper was supported by the Program for the Philosophy and Social Sciences Research of Higher Learning Institutions of Shanxi under Grant no. 201801032.

\section{References}

[1] V. Babich and P. Kouvelis, "Introduction to the special issue on research at the interface of finance, operations, and risk management (IForm): recent contributions and future directions," Manufacturing \& Service Operations Management, vol. 20 , no. 1, pp. 1-18, 2018.

[2] L. Klapper, "The role of factoring for financing small and medium enterprises," Journal of Banking \& Finance, vol. 30, no. 11 , pp. 3111-3130, 2006.

[3] J. K. Smith and C. Schnucker, "An empirical examination of organizational structure: the economics of the factoring decision," Journal of Corporate Finance, vol. 1, no. 1, pp. 119-138, 1994.

[4] S. L. Mian and C. W. Smith, "Accounts receivable management policy: theory and evidence," The Journal of Finance, vol. 47, no. 1, pp. 169-200, 1992.

[5] K. Soufani, "On the determinants of factoring as a financing choice: evidence from the UK," Journal of Economics and Business, vol. 54, no. 2, pp. 239-252, 2002.

[6] G. Asselbergh, "Financing firms with restricted access to financial markets: the use of trade credit and factoring in Belgium," The European Journal of Finance, vol. 8, no. 1, pp. 2-20, 2002.

[7] D. A. Wuttke, C. Blome, and M. Henke, "Focusing the financial flow of supply chains: an empirical investigation of financial supply chain management," International Journal of Production Economics, vol. 145, no. 2, pp. 773-789, 2013.

[8] B. J. Sopranzetti, "The economics of factoring accounts receivable," Journal of Economics and Business, vol. 50, no. 4, pp. 339-359, 1998.

[9] M. Auboin, H. Smythe, and R. Teh, Supply Chain Finance and SMES: Evidence from International Factoring Data, CESifo, Munich, Germany, 2016, https://ssrn.com/abstract=2845280.

[10] B. Summers and N. Wilson, "Trade credit management and the decision to use factoring: an empirical study," Journal of Business Finance \& Accounting, vol. 27, no. 1-2, pp. 37-68, 2000.

[11] H.-S. Lau and A. H.-L. Lau, "Manufacturer's pricing strategy and return policy for a single-period commodity," European Journal of Operational Research, vol. 116, no. 2, pp. 291-304, 1999.

[12] X. H. Gan, S. P. Sethi, and H. M. Yan, "Channel coordination with a risk-neutral supplier and a downside-risk-averse retailer," Production \& Operations Management, vol. 14, no. 1, pp. 80-89, 2010.
[13] W. Jin and J. Luo, “Optimal inventory and insurance decisions for a supply chain financing system with downside risk control," Applied Stochastic Models in Business and Industry, vol. 33, no. 1, pp. 63-80, 2017.

[14] X. Chen and A. Wang, "Trade credit contract with limited liability in the supply chain with budget constraints," Annals of Operations Research, vol. 196, no. 1, pp. 153-165, 2012.

[15] S. A. Yang and J. R. Birge, "How inventory is (should be) financed: trade credit in supply chains with demand uncertainty and costs of financial distress," 2013, http://ssrn.com/ abstract $=2746645$.

[16] E. Cao and M. Yu, "Trade credit financing and coordination for an emission-dependent supply chain," Computers \& Industrial Engineering, vol. 119, pp. 50-62, 2018.

[17] P. Kouvelis and W. Zhao, "Financing the newsvendor: supplier vs. bank, and the structure of optimal trade credit contracts," Operations Research, vol. 60, no. 3, pp. 566-580, 2012.

[18] B. Jing, X. Chen, and G. G. Cai, "Equilibrium financing in a distribution channel with capital constraint," Production and Operations Management, vol. 21, no. 6, pp. 1090-1101, 2012.

[19] G. G. Cai, X. Chen, and Z. Xiao, "The roles of bank and trade credits: theoretical analysis and empirical evidence," Production and Operations Management, vol. 23, no. 4, pp. 583-598, 2014.

[20] F. Tanrisever, H. Cetinay, M. Reindorp et al., "Reverse factoring for SME finance," 2015, https://ssrn.com/abstract=2183991.

[21] K. V. D. Vliet, M. J. Reindorp, and J. C. Fransoo, "The price of reverse factoring: financing rates vs. payment delays," European Journal of Operational Research, vol. 242, no. 3, pp. 842-853, 2015.

[22] K. V. D. Vliet, M. J. Reindorp, and J. C. Fransoo, "Improving service levels through reverse factoring," 2015, https://ssrn. com/abstract $=2694242$.

[23] S. D. Lekkakos and A. Serrano, "Supply chain finance for small and medium sized enterprises: the case of reverse factoring," International Journal of Physical Distribution \& Logistics Management, vol. 46, no. 4, pp. 367-392, 2016.

[24] T. I. Tunca and W. Zhu, "Buyer intermediation in supplier finance," Management Science, vol. 64, no. 12, pp. 5461-5959, 2018.

[25] H. Huang and J. Zhang, "Recourse accounts receivable factoring financing ratio research based on multinational supply chain," in Proceeding of the International Conference on Service Systems and Service Management, B. Yang, Ed., pp. 1-4, IEEE, Kunming, China, June 2016.

[26] Y. Li and C. Gu, "Factoring policy with constant demand and limited capital," International Transactions in Operational Research, 2018, In press.

[27] P. Kouvelis and F. Xu, "A supply chain theory of factoring and reverse factoring," 2018, https://ssrn.com/abstract=3241484.

[28] P. Kouvelis and W. Zhao, "Who should finance the supply chain? Impact of credit ratings on supply chain decisions," Manufacturing \& Service Operations Management, vol. 20, no. 1, pp. 19-35, 2017.

[29] B. Zhang, D. D. Wu, and L. Liang, "Optimal option ordering and pricing decisions with capital constraint and default risk," IEEE Systems Journal, vol. 11, no. 3, pp. 1-11, 2015.

[30] M. A. Lariviere and E. L. Porteus, "Selling to the newsvendor: an analysis of price-only contracts," Manufacturing \& Service Operations Management, vol. 3, no. 4, pp. 293-305, 2001. 


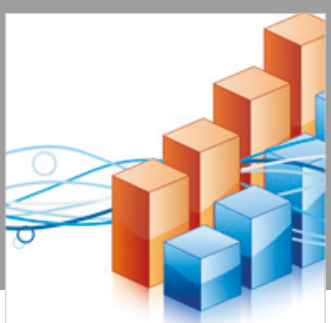

Advances in

Operations Research

\section{-n-m}
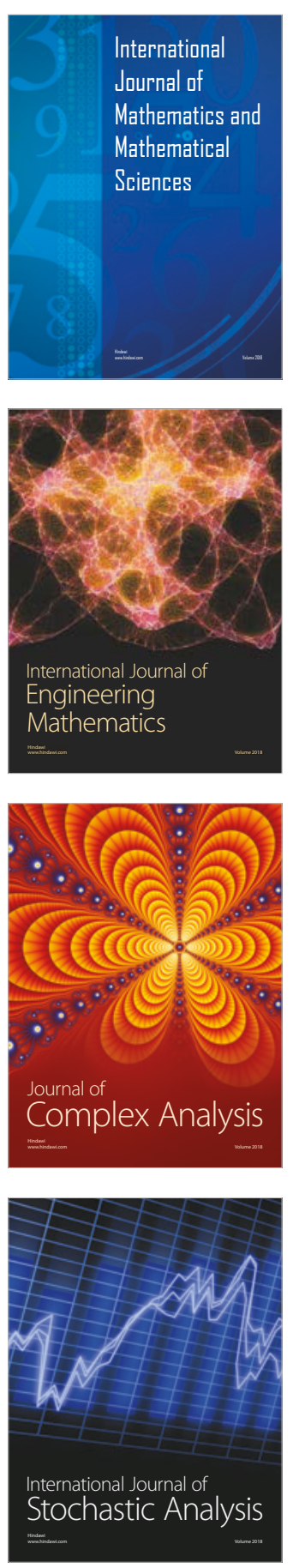
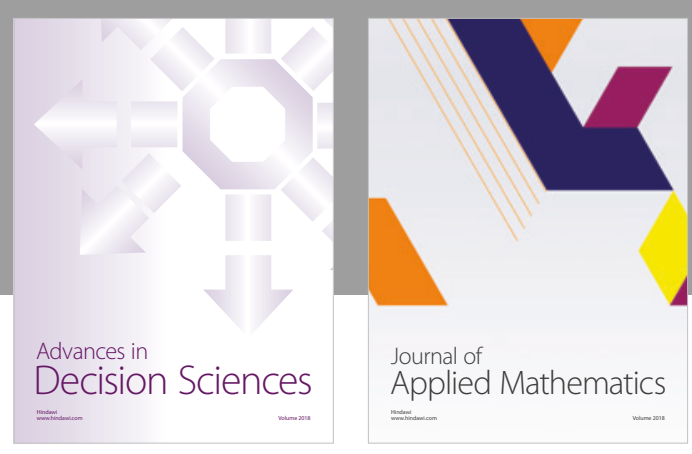

Journal of

Applied Mathematics
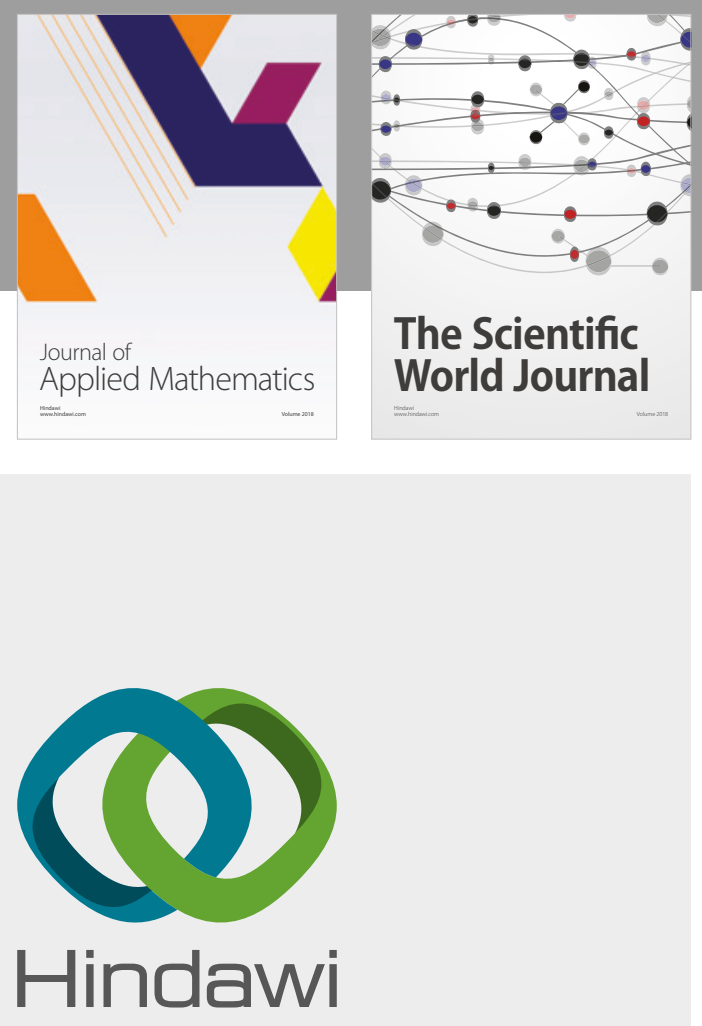

Submit your manuscripts at

www.hindawi.com

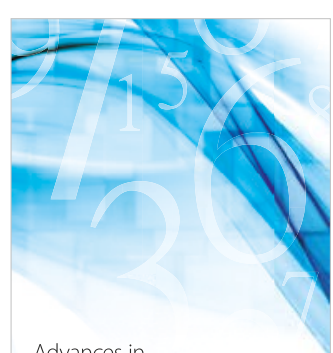

Advances in
Numerical Analysis
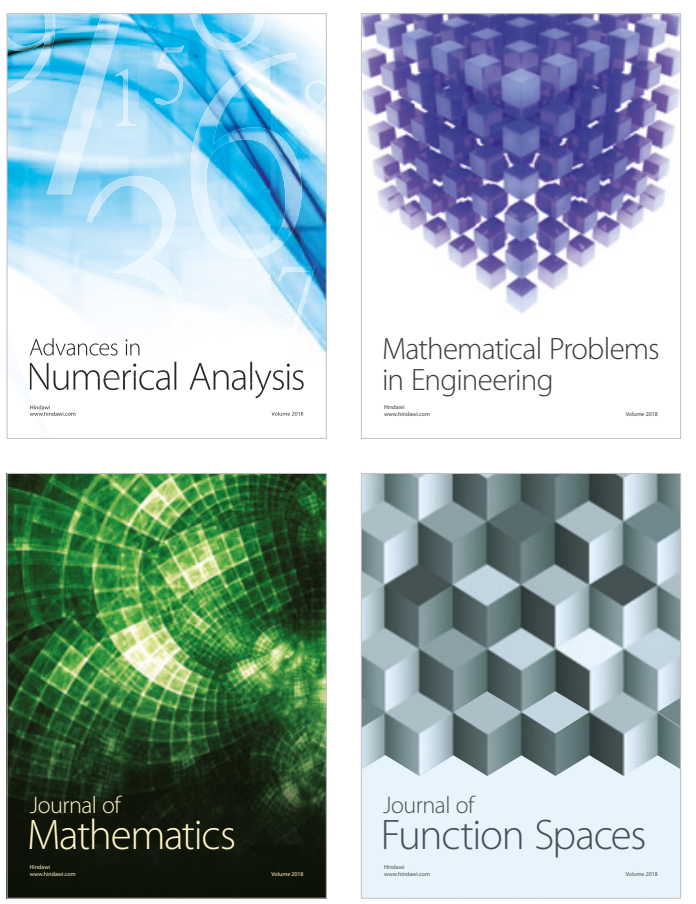

Mathematical Problems in Engineering

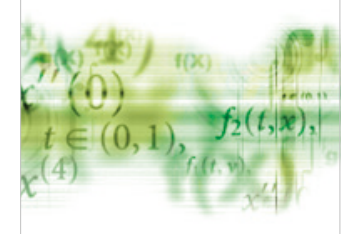

International Journal of

Differential Equations

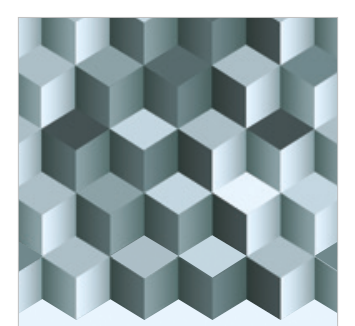

Journal of

Function Spaces

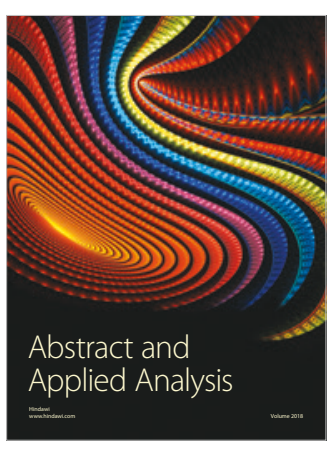

The Scientific

World Journal

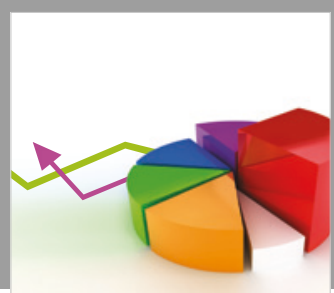

Journal of

Probability and Statistics
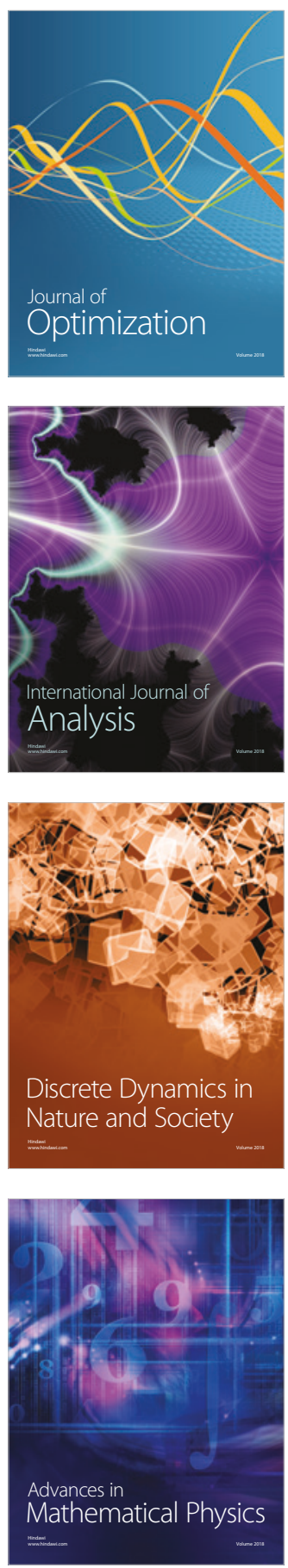